\title{
El Perú y sus vecinos: fundamentos para una cultura de paz
}

\author{
Álvaro González Riesle ${ }^{1}$ \\ Pontificia Universidad Católica del Perú
}

Dirigiéndose a fundamentar el diseño de estrategias para instaurar una Cultura de Paz en las relaciones entre el Perú y sus países vecinos, se realizó una investigación con 409 estudiantes de Educación (159 de una universidad privada y 250 de una pública). Se evaluaron las relaciones entre las seis variables independientes: Dogmatismo $(D O G)$, Autoritarismo de Derecha $(R W A)$, Dominación Social $(O S D)$, Maquiavelismo $(M A Q)$, Nacionalismo $(N A C)$ y Patriotismo $(P A T)$, con las variables dependientes representadas en percepciones sobre las actitudes hacia el Perú en las áreas de: Cortesía, No Probabilidad de Guerra, Confiabilidad, Solidaridad y Cooperatividad-Conflictividad percibidas en cinco países limítrofes: Ecuador, Colombia, Brasil, Bolivia y Chile. Se aplicaron seis cuestionarios de actitudes tipo Likert y un Diferencial Semántico. Los resultados confirman solo parcialmente la hipótesis planteada. Las variables independientes no configuran un modelo predictor aceptable. Solo destacan individualmente el Autoritarismo de Derecha $(R W A)$ como predictor de las percepciones de Probabilidad de Guerra con Chile, y el Patriotismo (PAT) respecto a la Cortesía, No Probabilidad de Guerra, Confianza, Solidaridad y Cooperatividad-Conflictividad en el caso de Bolivia. El PAT se relacionó directamente con $R W A$, e inversamente con el SDO, ambos componentes de la Ideología Conservadora $(I C)$. En el Diferencial Semántico $(D S)$, las percepciones de las actitudes hacia el Perú de cuatro países: Ecuador, Colombia, Brasil y Bolivia se acumularon más cerca del polo favorable y las de Chile, al polo desfavorable. En base a los hallazgos se brindaron recomendaciones para el diseño de estrategias de Investigación y Educación para la Paz

Palabras clave: Cultura de Paz, Educación para la Paz, Actitudes, Diferencial Semántico, Distancia Semántica

Peru and its neighbors: fundaments for a peace culture

Aiming at grounding the design of a Peace Culture strategy for the relationships among Peru and its bordering countries, a research was developed in 409 Education students: 159 from a private and 250 from a public university. Relationships among six independent variables: Dogmatism (DOG), Right-Wing Authoritarianism (RWA), Social Domination (SDO), Machiavellianism $(M A Q)$, Nationalism $(N A C)$ and Patriotism (PAT) with five dependent variables (perception on attitudes towards Peru in the areas of: Courtesy, Non-Probability of War, Trustworthiness, Solidarity and Cooperativeness-Conflictiveness) as perceived in five bordering countries: Ecuador, Colombia, Brazil, Bolivia, and Chile, were assessed. Six Likert-type attitude questionnaires and a Semantic Differential (DS) were applied. Descriptive and correlational analysis were developed and semantic distance matrices were

1 Magíster en Psicología por University of Kansas. Profesor del Departamento de Psicología de la Pontificia Universidad Católica del Perú. Dirección postal: Edificio Los Sauces 604-Residencial San Felipe. Jesús María, Lima. Perú. Contacto: a_gonzal@pucp.edu.pe. 
structured among the above mentioned countries. The results only partially confirm the proposed hypothesis. The independent variables did not integrate an acceptable predictive model. Only the RWA appears as a predictor for the perceptions on Non-Probability of War with Chile, and Patriotism as predictor for the perceptions on Courtesy,Non-Probability of War ,Trustworthiness, Solidarity and Cooperativeness-Conflictiveness in the case of Bolivia. As far as the Conservative Ideology $(I C)$ was concerned, a direct relationship between PAT and the ICs RWA component, and a reverse relation with SDO were registered. The attitudes towards Peru's perceptions related to Ecuador, Colombia, Brazil and Bolivia accumulated themselves nearer to the favorable pole of Semantic Differential (DS) , and the corresponding to Chile were located nearer to the unfavorable pole. On the basis of these findings, recommendations were offered on Peace Research and Education strategies. Keywords: Peace Culture, Peace Education, Attitudes, Semantic Differential, Semantic Distance.

\section{Le Pérou et ses voisins: les fondements d'une culture de la paix}

Dans le but de fonder la conception de stratégies pour établir une culture de la paix dans les relations entre le Pérou et ses pays voisins, une enquête a été menée auprès de 409 étudiants en éducation (159 d'une université privée et 250 d'une université publique). Les relations entre les six variables indépendantes ont été évaluées: dogmatisme (DOG), autoritarisme de droite (RWA), domination sociale (OSD), machiavélisme (MAQ), nationalisme (NAC) et patriotisme (PAT), les variables dépendantes étant représentées dans les perceptions. sur les attitudes envers le Pérou dans les domaines suivants: Courtoisie, Pas de probabilité de guerre, Fiabilité, Solidarité et Coopérativité - Conflit perçu dans cinq pays frontaliers: Équateur, Colombie, Brésil, Bolivie et Chili. Six questionnaires d'attitude de type Likert et un différentiel sémantique ont été appliqués. Les résultats ne confirment que partiellement l'hypothèse soulevée. Les variables indépendantes ne configurent pas un modèle de prédicteur acceptable. Seul le droit autoritarisme (RWA) se démarque individuellement en tant que prédicteur des perceptions de la probabilité de guerre avec le Chili et du patriotisme (PAT) en ce qui concerne la courtoisie, l'absence de probabilité de guerre, la confiance, la solidarité et la coopération - conflit dans le cas de la Bolivie. PAT était directement lié à RWA, et inversement à SDO, les deux composants de l'idéologie conservatrice $(\mathrm{CI})$. Dans le différentiel sémantique (SD), les perceptions des attitudes à l'égard du Pérou dans quatre pays: l'Équateur, la Colombie, le Brésil et la Bolivie se sont accumulées plus près du pôle favorable et celles du Chili, du pôle défavorable. Sur la base des résultats, des recommandations ont été formulées pour la conception de stratégies de recherche et d'éducation pour la paix.

Mots clés: culture de la paix, éducation pour la paix, attitudes, différentiel sémantique, distance sémantique

\section{Peru e seus vizinhos: bases para uma cultura de paz}

Com o objetivo de fundamentar o desenho de estratégias para o estabelecimento de uma Cultura de Paz nas relaçôes entre o Peru e seus países vizinhos, foi realizada uma investigação com 409 alunos da Educação (159 de uma universidade privada e 250 de uma pública). As relaçóes entre as seis variáveis independentes foram avaliadas: Dogmatismo (DOG), Autoritarismo de Direita (RWA), Dominação Social (OSD), Maquiavelismo (MAQ), Nacionalismo (NAC) e Patriotismo (PAT), com as variáveis dependentes representadas nas percepçóes sobre as atitudes em relação ao Peru nas áreas de: Cortesia, Sem Probabilidade 
El Perú y sus vecinos: fundamentos para una cultura de paz / González Riesle

de Guerra, Confiabilidade, Solidariedade e Cooperatividade-Conflito percebido em cinco países limítrofes: Equador, Colômbia, Brasil, Bolívia e Chile. Seis questionários de atitude do tipo Likert e um Diferencial Semântico foram aplicados. Os resultados confirmam apenas parcialmente a hipótese levantada. As variáveis independentes não configuram um modelo de preditor aceitável. Apenas o Autoritarismo de Direito (RWA) se destacam individualmente como preditor das percepçóes de Probabilidade de Guerra com o Chile e Patriotismo (PAT) no que diz respeito à Cortesia, Sem Probabilidade de Guerra, Confiança, Solidariedade e Cooperatividade-Conflito no caso da Bolívia. PAT estava diretamente relacionado ao RWA, e inversamente ao SDO, ambos componentes da Ideologia Conservativa (IC). No Diferencial Semântico (SD), as percepçóes de atitudes em relação ao Peru em quatro países: Equador, Colômbia, Brasil e Bolívia acumularam-se mais perto do pólo favorável e as do Chile, do pólo desfavorável. Com base nas conclusóes, foram fornecidas recomendaçóes para a concepção de estratégias de Pesquisa e Educação para a Paz.

Palavras-chave: Cultura de Paz, Educação para a Paz, Atitudes, Diferencial Semântico, Distância Semântica 
A lo largo de su historia republicana, las relaciones entre el Perú y sus países limítrofes han experimentado tensiones de diversa intensidad. La mayor conflictividad se ha registrado en su interacción con Chile y Ecuador y la menor con Colombia, Brasil y Bolivia, lo cual sugiere la necesidad del análisis psicosocial de la influencia que estas experiencias podrían ejercen en (a) las imágenes o actitudes mutuas entre los países involucrados, (b) las conductas de cooperación o competencia internacionales, (c) la xenofobia y (d) la integración latinoamericana

\section{Relaciones Perú - Chile}

La historia de las relaciones entre Perú y Chile ha registrado fluctuaciones entre los polos del conflicto y la cooperación. La más antigua relación conflictiva registrada data de la invasión inca al territorio de Arauco, al cual los naturales opusieron una férrea resistencia que paralizó el avance incaico en el río Maule. Durante los años iniciales de la conquista española se vieron teñidos por las reyertas entre pizarristas y almagristas, a quienes llamaban "los de Chile".

El periodo colonial, durante el cual el Imperio incaico devino en Virreinato y Chile en Capitanía General, se caracterizó por la actitud derogatoria y excluyente de los peruanos hacia los pobladores de Chile, lo cual originó resentimiento en los chilenos.

$\mathrm{Al}$ iniciarse las guerras de la Independencia, Chile contribuyó a la estructuración de la expedición libertadora de San Martín al Perú con hombres y pertrechos. Iniciada la República, el Mariscal Andrés de Santa Cruz intentó reunificar el Perú y Bolivia creando la Confederación Perú-Boliviana, la que fue vista con desconfianza por Chile. Este factor contribuyó a agudizar la competencia comercial entre los puertos del Callao en el Perú y de Valparaíso en Chile. Al final, Chile envió dos expediciones para destruir la Confederación. La primera, al mando de Manuel Blanco Encalada y la segunda a cargo de Manuel 
Bulnes que terminó con la victoria chilena en Yungay y marcó el fin de la Confederación.

En 1866, Perú y Chile unieron sus fuerzas para repeler el intento de España por recuperar las colonias perdidas. Pero esta cooperación fue efímera y las tensiones se fueron intensificando hasta eclosionar en la Guerra del Pacífico en 1879, que concluyó con la firma del Tratado de Ancón. Después de 49 años de ocupación chilena de las provincias de Tacna, Arica y Tarapacá se fijó la frontera (denominada "Línea de la Concordia") entre Perú y Chile mediante el Tratado de 1929, que consagró la fórmula "Tacna para el Perú y Arica para Chile”. Desde entonces hasta el presente, la interacción entre ambos países ha experimentado altibajos, con picos de cooperación en el caso de la defensa mancomunada de la iniciativa del presidente Bustamante y Rivero, quien proclamó la soberanía nacional dentro de las 200 millas marítimas; y, en el polo opuesto, con la ocurrencia de incidentes críticos de diversa índole, tales como la exhibición en los aviones de la línea aérea chilena LAN de un video considerado como ofensivo para el Perú, la decisión de Chile de patentar el pisco y el postre denominado Suspiro de Limeña como propios, la detección de actos de espionaje chileno, etc.

La desconfianza mutua entre Perú y Chile (Kahhat, 2006) se ha visto intensificada por factores tales como: a) El imperativo planteado por el Primer Ministro chileno Diego Portales de asegurar para Chile una posición de predominio en el Pacífico Sur y b) La presunción de Chile de que el Perú es un estado irredentista que jamás aceptará como un hecho consumado la pérdida territorial que sufriera durante la Guerra del Pacífico.

Las tensiones que han caracterizado la relación histórica PerúChile encuentran su correlato en las actitudes e imágenes mutuas entre ambos pueblos. Mediante el análisis de textos escolares chilenos de historia, Parodi (2010) propuso un modelo para entender las relaciones entre Chile, Perú y Bolivia, en el que Chile asume el rol subordinante y Perú y Bolivia, el rol de naciones subordinadas. La autoimagen de Chile se caracteriza por atribuciones de: civilización, desarrollo económico, 
orden político, proyecto nacional exitoso, predominio de lo blancooccidental y homogeneidad racial. Por el contrario, la heteroimagen de Perú-Bolivia incluye las atribuciones de barbarie, subdesarrollo económico, caos político, proyectos nacionales fracasados, predominio de lo indio y lo indígena y heterogeneidad racial. El modelo de Parodi sugiere la existencia en la perspectiva chilena de una actitud etnocéntrica y desfavorable hacia el exogrupo (integrado por Perú y Bolivia) y reafirma una relación vertical y jerarquizada entre ambas instancias.

Analizando las actitudes hacia la guerra (militarismo), en universitarios peruanos Sirlopú y León, (1996), detectaron una relación significativa entre el apoyo de la dominancia de unos grupos sobre otros, la oposición a la igualdad entre grupos en una sociedad y un fuerte nacionalismo, por un lado, y actitudes más favorables hacia la guerra, por el otro. Por el contrario, los universitarios que se identificaron más con su nación evidenciaron menos apoyo a la guerra, siendo este último un resultado contrario a lo esperado.

Comparando experimentalmente las percepciones sobre Perú y Chile en estudiantes peruanos, Genna et al. (2010) detectaron los aspectos en los que se atribuye una superioridad de los chilenos sobre los peruanos, que comprenden un mayor nivel de desarrollo económico y orden social, así como una mayor homogeneidad étnica y racial y una superioridad en el aspecto militar. Por otra parte, los aspectos en los que los participantes refirieron una superioridad de los peruanos sobre los chilenos son: a) la riqueza natural y tradición cultural del Perú expresados en su cultura culinaria, historia y recursos naturales. b) la simpatía y sociabilidad de los miembros del endogrupo, lo que podría resumirse en una expresión del colectivismo peruano. c) su creatividad como medio de subsistencia.

La desconfianza entre ambos países aún permanece, a pesar de los esfuerzos aplicados para reducirla. En la evaluación de imágenes mutuas en blogs peruanos y chilenos (González, 2011) se han detectado intensas y variadas manifestaciones de hostilidad, que contribuyen a respaldar la vigencia de la dinámica expansionismo-revanchismo en las imágenes entre Chile y el Perú en los blogs analizados. Paralelamente, 
se detectaron contenidos correspondientes a actitudes favorables a la integración entre ambos países.

Analizando la actitud defensiva en lo militar y económico del Perú frente a Chile en poblaciones estudiantiles de Tacna, Ibáñez (2011) sugirió la existencia de una relación directa en esta actitud de variables identitarias tales como: grado de prominencia subjetiva del conflicto, valoración de los peruanos, valoración de personajes históricos, grado de identificación con el Perú; y de una relación inversa de la variable de simpatía por los chilenos. Al evaluar la influencia de las variables independientes sobre el revanchismo peruano en Tacna, aparece únicamente la valoración de los chilenos como ejerciendo una influencia inversa sobre esta variable dependiente. En base a la evidencia recolectada, la autora sugiere que:

“...no es tan sencillo como sostener que los tacneños poseen actitudes más hostiles hacia Chile que los limeños o al revés. En ambas ciudades las actitudes hostiles o defensivas hacia el vecino país parecen responder a procesos psicológicos, sociales e históricos significativamente distintos y bastante menos sencillos de lo que inicialmente se había propuesto" (Ibáñez, 2011, p.36).

Posteriormente, las imágenes sobre el hombre y la sociedad peruanos y chilenos fueron estudiados por Zambrano et. al (2017) en una muestra de universitarios chilenos. Los respondientes percibían la sociedad chilena como más moderna, democrática, cercana al primer mundo, en comparación con la peruana, pero los niveles de corrupción y de pobreza fueron percibidos como muy semejantes en los dos países. En tanto que el chileno fue valorado como competitivo, el peruano recibió un puntaje superior como emprendedor.

Mediante el estudio de las percepciones de dos muestras de población, una peruana y otra chilena, Valencia-Moya et al. (2018) detectaron una relación positiva entre las ideologías autoritaria y dominante y un mayor prejuicio hacia el exogrupo. Ello se observa tanto en el análisis de las actitudes de la población peruana como en la chilena. Paralelamente, los autores observaron que una representación 
identitaria positiva sobre el propio país tiene un efecto positivo en la representación del otro país: no exacerba los estereotipos y reduce el prejuicio.

Al estudiar las actitudes en Chile de chilenos hacia los inmigrantes peruanos, Gonzalez et al. (2010) registraron una relación inversa entre frecuencia de contacto y prejuicio. Cuanto mayor el contacto que los peruanos tenían con los chilenos, menor era su prejuicio hacia ellos. El contacto reducía el prejuicio porque reducía la ansiedad intergrupal y la amenaza realista hacia los miembros del exogrupo. Adicionalmente, cuanto más se identificaban los chilenos con América Latina, expresaban menos prejuicio hacia los inmigrantes peruanos. Los resultados anotados sugieren que el contacto puede reducir la segregación e incrementar la complejidad de la representación del agregado, reduciendo la posibilidad de emergencia de estereotipos y prejuicios.

\section{Relaciones Perú-Ecuador}

El conflicto fronterizo Perú-Ecuador, que terminó en 1998, enfrentaba dos políticas exteriores contradictorias, enraizadas en imágenes de la historia y de la razón jurídica, que insinuaban, por el lado ecuatoriano, su pretensión de acceder al Amazonas como objetivo nacional, y por el lado peruano, la necesidad de ejecutar y afianzar el protocolo de Rio de Janeiro (Bonilla,1999). Los esfuerzos para llegar a un acuerdo entre ambos países se vieron obstaculizados por factores tales como: a) un intenso nacionalismo en ambas partes, y b) El "peso de la historia", que remonta el origen de la disputa al periodo colonial español e incluye repetidas, si bien intermitentes y finalmente fracasadas iniciativas de resolución a lo largo de la historia de los dos países como naciones independientes (Palmer, 1999). Los Acuerdos de Paz de Brasilia firmados en 1998 por ambos países permitieron que el Perú obtuviera la demarcación final de la frontera a lo largo de la separación de aguas de la Cordillera del Cóndor .Ecuador obtuvo una pequeña porción de territorio Cusimaza-Bomboisa-Yaupi, propiedad privada de un kilómetro cuadrado en Tiwinza y acceso a él y derechos de nave- 
gación sobre el Amazonas y sus afluentes así como infraestructura y áreas de almacenamiento para propósitos múltiples en ubicaciones designadas a lo largo de ello. Adicionalmente, los Acuerdos permitieron construir un conjunto de medidas de confianza y seguridad mutuas, celebrar un acuerdo de comercio y navegación, y suscribir un acuerdo amplio de integración fronteriza, desarrollo y vecindad, cuya ejecución ha sido altamente positiva, superando toda expectativa (Novak \&Namihas, 2010).

Con el fin de evaluar la relación existente entre este pasado conflictivo y las imágenes mutuas Perú-Ecuador, Escurra y Trelles (1988) aplicaron una encuesta a 370 alumnos de quinto año de educación secundaria en Lima para caracterizar las imágenes que dicho grupo de estudiantes tenía sobre los nacionales de cinco países limítrofes con el Perú: ecuatorianos, chilenos, bolivianos, brasileños y colombianos. Se les pidió que asociaran una serie de características con cada uno de los pueblos de la lista. Se encontró que los interpelados percibían a los ecuatorianos como desleales, autosuficientes e individualistas, a los chilenos como trabajadores, a los bolivianos como trabajadores, valientes y responsables. a los brasileños como simpáticos, bondadosos, deseables y queridos. Con respecto a los colombianos, las actitudes hacia ellos permanecían en la zona de la neutralidad.

Los encuestados consideraron más deseable una interacción social con un chileno que con un ecuatoriano. Denotaban actitudes etnocéntricas solamente en la percepción del pueblo ecuatoriano, caracterizadas por la tendencia de los grupos sociales a considerarse a sí mismos en forma positiva y a valorar a grupos sociales externos en forma negativa.

La visión inversa - de los ecuatorianos respecto a los peruanosfue analizada por Durán Barba (1992) en una muestra nacional de la población ecuatoriana, integrada por 1760 ciudadanos mayores de 18 años, de zonas urbanas y rurales de 15 provincias de Ecuador. Los resultados obtenidos señalan que la mayoría de los encuestados piensa que los ecuatorianos son más inteligentes, trabajadores, valientes, preparados y honrados; y menos violentos y falsos que los peruanos. 
La mayoría de los interrogados prefería hacer negocios con colombianos antes que con peruanos. Los prejuiciados contra el Perú eran proporcionalmente más numerosos, entre las mujeres; entre los mayores de 53 años y menos en los que tenían entre 18 y 27 años y en los estratos sociales más bajos y en el nivel educativo sin educación primaria. La intensidad del prejuicio antiperuano era menor en los estratos mejor informados y mayor en los que tienen menos información sobre el Perú. En general, mostraron aversión hacia el Perú el 74\% de los encuestados, pero el $84 \%$ quería una solución definitiva para el diferendo limítrofe que se produjo posteriormente. Por otra parte, se detectó una actitud etnocéntrica con respecto al Perú en la población encuestada.

La imagen del Perú en los textos escolares ecuatorianos fue posteriormente analizada por Malpica y González (1997). En este estudio cabe resaltar la faceta psicosocial correspondiente a los juicios y adjetivos denigrantes sobre el Perú, incluidos en los textos escolares mencionados, bajo la forma de epítetos que señalan a los peruanos como causantes de todos los males ecuatorianos y como el "enemigo a eliminar". Dichas referencia motivan en el lector joven cinco clases de actitudes: La "victimización" del Ecuador, la atribución al estado peruano de una voluntad expansionista, la atribución a los peruanos de un estereotipo denigrante, el resentimiento hacia los peruanos y un "deseo de revancha". Culminó su trabajo invocando al Gobierno de Ecuador para que dispusiese la eliminación de los juicios y adjetivos denigrantes al Perú y los peruanos contenidos en textos escolares y otros materiales de enseñanza del mencionado país. Pidió además que Ecuador, Perú y todos los países miembros de la UNESCO abordasen la preparación de los planes integrados sobre educación para la paz, los derechos humanos y la democracia, encaminados a la construcción de una cultura de paz que prevenga conflictos, que salvaguarde la vida y la civilización humana, como parte fundamental de los derechos humanos y los derechos del niño. 


\section{Relaciones Perú-Colombia}

La relación peruano-colombiana estuvo marcada por el enfrentamiento y el recelo, y en el mejor de los casos por la indiferencia hasta la segunda mitad del siglo XX (Novak \& Namihas, 2011). Debido a la exigencia por parte de Bolívar de la restitución de las provincias de Jaén y Maynas, en 1828 estalló la Guerra contra la Gran Colombia que culminó con la desocupación por parte del Perú de Guayaquil y Loja. Los conflictos territoriales fueron finalmente zanjados en 1922 mediante el Tratado Salomón-Lozano mediante el cual Perú cedió a Colombia el Trapecio de Leticia. Sin embargo, el incumplimiento por parte de Colombia del art. 8 del Tratado, así como las hostilidades puestas en práctica contra la navegación y el tráfico comercial peruanos, determinaron que, en la noche del 31 de agosto al 1 de setiembre de 1932, un grupo de peruanos armados ocupase Leticia. En 1933 Colombia rompió relaciones diplomáticas con el Perú y se produjeron acciones armadas. El conflicto terminó con la suscripción en 1934 del Protocolo de Paz, Amistad y Cooperación de Rio de Janeiro y la entrega de Leticia a las autoridades colombianas.

Durante el gobierno de Manuel A. Odría el líder aprista Víctor Raúl Haya de la Torre solicitó asilo en la Embajada de Colombia (Novak $\&$ Namihas,2011). El gobierno peruano negó a Colombia la capacidad para calificarlo unilateralmente como asilado. Se sometió el diferendo al arbitraje de la Corte Internacional de Justicia de La Haya. Finalmente, en 1954 se convino en que Haya de la Torre abandonara la Embajada de Colombia en Lima previa entrega simbólica del asilado a la jurisdicción peruana antes de abordar el avión que lo conduciría a México.

En 1989, los presidentes Alan García del Perú y Virgilio Barco de Colombia suscribieron varios convenios de cooperación en las áreas de: telecomunicaciones fronterizas, preservación y protección de bienes históricos, culturales y arqueológicos, exploración petrolera conjunta y lucha contra el narcotráfico, el terrorismo y el tráfico ilícito de armas. Con ello se imprimió un dinamismo sin precedentes a la relación entre ambos países. 
La relación política-diplomática peruano-colombiana ha alcanzado un extraordinario nivel, habiéndose establecido diversos mecanismos de diálogo político destinados a su mantenimiento y profundización (Novak \& Namihas, 2011). Asimismo, la continuidad de las visitas oficiales pone en evidencia el interés de ambos países por mantener una relación privilegiada y diversificada, en beneficio de sus respectivas poblaciones.

A todo esto, se debe agregar el conjunto de mecanismos de cooperación e integración fronteriza creados por ambos países y destinados al mejoramiento de las condiciones de vida de las poblaciones que ahí se encuentran (Novak \& Namihas, 2011). Se trata de un espacio de más de 160,000 km², donde ambos países vienen efectuando planes y programas de desarrollo económico y social, prestación de servicios básicos y desarrollo productivo e infraestructura. El logro cabal de los objetivos de la integración fronteriza se ha visto menoscabado por el acciones meramente declarativas, centralismo y la escasa participación de los gobiernos locales (Hurtado \& Aponte, 2017).

La dimensión psicosocial de las relaciones Perú-Colombia se ha visto reflejada en una investigación de Echeverri et al. (2015), quienes analizaron el posicionamiento de Colombia en las actitudes de visitantes peruanos, compuestas por asociaciones positivas y negativas. Los que percibían a Colombia positivamente la asociaban con las ideas de: montañas, aves, ríos y piedras preciosas; turismo, café, artistas, deportistas, gente acogedora. sociable, divertida y orgullosos de su país. Las asociaciones negativas la vinculan con: Crimen, Drogas, Narcotráfico y Guerrilla. El estudio subrayó las repercusiones que tiene la imagen país de Colombia en el turismo, las exportaciones y la inversión extranjera, así como la importancia de una imagen positiva para mejorar la reputación de Colombia en los mercados internacionales y para definir estrategias de marketing territorial. 


\section{Relaciones Perú-Brasil}

En 1909 se firmó el Tratado Velarde-Rio Branco que fijó los límites entra ambos países. Los buenos oficios de Brasil para el logro de la paz entre Perú y Ecuador después del conflicto de 1941 se hicieron evidentes al actuar como garante del Protocolo de Rio de Janeiro de 1942 y en el arreglo definitivo contenido en los Acuerdos de Paz de Brasilia de 1998 (Novak \& Namihas, 2012). La necesidad de fomentar una cultura de paz e integración fronteriza incentivando la identidad nacional y cultural y el desarrollo sostenible fueron motivo del Acuerdo Marco para el establecimiento de una Zona de Integración Fronteriza del 2009.

En lo referente a la arista psicosocial, son escasas las investigaciones sobre imágenes mutuas entre Perú y Brasil. En 2011, Maldonado y Crow (2011) analizaron los niveles de afinidad hacia diferentes países en el mundo, pidiendo a los encuestados que valoraran numéricamente a distintos países a nivel mundial en una escala que iba desde $0=$ Opinión muy desfavorable hasta 100=Opinión muy favorable. Los respondientes de Brasil otorgaron al Perú 37 puntos, y los del Perú, 62 puntos a Brasil. Las percepciones no eran simétricas, siendo la opinión que Brasil tenía del Perú más desfavorable que la que el Perú tenía de Brasil. Brasil obtuvo el mayor puntaje promedio entre todos los países de la lista por lo que puede afirmarse que era percibido como el líder indiscutible de la región en lo referente a simpatías, siguiéndole Argentina y Chile y siendo además considerado como el país que ejercerá mayor influencia en la región.

\section{Relaciones Perú-Bolivia}

Durante el Incanato y el coloniaje, el territorio que hoy corresponde a Bolivia estuvo unido al territorio peruano bajo las denominaciones del Collasuyo y de la Audiencia de Charcas, respectivamente. En la etapa inicial de la República, ambos países intentaron unirse en base a la idea de la Confederación Peruano-Boliviana, proyecto que fue destruido por dos intervenciones militares de Chile en territorio peruano 
(Novak \& Namihas, 2013). En 1866 Perú y Bolivia se unieron en la Cuádruple Alianza con Chile y Ecuador ante la amenaza de la reconquista espańola de sus antiguas posesiones. La guerra culminó con el combate del Dos de Mayo en el Callao. En 1879 estalló la Guerra del Pacífico en la que Perú y Bolivia actuaron como aliados contra Chile y que tuvo como resultado la pérdida para el Perú de Arica y Tarapacá.

Los límites entre Perú y Bolivia fueron fijados en la primeras décadas del siglo XX, siendo el lago Titicaca un punto de convergencia entre ambos países. Los convenios de Ilo de 1992 eliminaron importantes barreras arancelarias y se incrementó el comercio bilateral. El Perú ha sido solidario con los intentos de Bolivia por conseguir materializar su aspiración de salida al mar.

Quedan como tareas el desarrollo de proyectos de integración energética, incrementar el comercio y el turismo bilateral y las inversiones recíprocas, reducir la xenofobia contra los inmigrantes peruanos en Bolivia, optimizar la integración fronteriza y la lucha contra el narcotráfico, el tráfico de armas y el contrabando (Novak \& Namihas, 2013).

En el imaginario peruano persisten tendencias a percibir a Bolivia; a) como un país que fue parte del Perú y que prefirió ser independiente, b) como de un Estado de menor importancia al nuestro, c) como un país desleal con el Perú, su aliado, durante la Guerra del Pacífico (Vidarte, 2014).

A lo largo de los siglos XIX al XXI, las interacciones conflictivas entre el Perú y sus países vecinos han venido siendo sustituidas por interacciones cooperativas que se evidencian en el incremento del intercambio comercial y cultural y en la emergencia de proyectos de integración de zonas fronterizas. El análisis y mejoramiento de las imágenes mutuas entre el Perú y sus países limítrofes constituye el complemento necesario para el diseño y aplicación de estrategias de integración dirigidas a la construcción de una Cultura de Paz en este ámbito.

En el diseño futuro de estrategias psicosociales de investigación dirigidas al mejoramiento de imágenes mutuas entre las naciones 
involucradas se requiere: (a) Distinguir entre la imagen del país y la imagen de los nacionales de dicho país, (b) Coordinar esfuerzos entre investigadores de los seis países, (c) Unificar la metodología de investigación de manera tal que se posibilite la obtención de resultados estadísticamente comparables, (d) Explorar las posibilidades de la futura medición de variables que podrían ser útiles para el diseño de estrategias de Educación para la Paz. Para tal efecto se proponen:

- Variables Independientes, tales como: Desarrollo Económico, Orden social, Homogeneidad étnica y racial, Superioridad militar y Modernización social.

A ello se agregarían: Autoritarismo, Dominancia, Nacionalismo, Identificación con su nación, Grado de Prominencia Subjetiva del conflicto, Valoración del Propio País, de los Propios Nacionales y Personajes Históricos, Contacto con el Exogrupo, Competitividad y Emprendedurismo.

- Variables Dependientes, tales como: Simpatía hacia el Exogrupo. Prejuicio hacia el Exogrupo y Actitud hacia a la Guerra.

A ello se agregarían atribuciones de rasgos al endogrupo y al exogrupo, tales como:

- Rasgos Positivos: Lealtad, Individualismo, Inteligencia, Laboriosidad, Coraje, Responsabilidad, Honradez, Confiabilidad, Sociabilidad, Simpatía, Bondad.

- Rasgos Negativos: Agresividad, Corruptibilidad

\section{Cultura de Paz}

La Cultura de Paz fue caracterizada por la resolución de las Naciones Unidas (A/RES/52/13/) como un conjunto de valores, actitudes y comportamientos que rechazan la violencia, e intentan prevenir conflictos a través de abordar sus causas primarias y que se esfuerzan por resolver problemas mediante el diálogo y la negociación, configurando un clima social facilitador para la cooperación tanto a nivel intra como internacional (Informe Mundial de Cultura de Paz, 2010). El ámbito de la cultura de paz a través de la educación es la principal prioridad 
para la mayor parte de organizaciones de la sociedad civil que han colaborado en el Decenio. Aun cuando siempre resulte difícil cuantificar los progresos, puede que este ámbito sea el factor más importante a largo plazo para la transición a una cultura de paz. Las actividades educativas de la sociedad civil, plasmadas en campañas, proyectos de solidaridad, conferencias, museos, publicaciones, webs en Internet, etc., han convencido a millones de personas de todo el mundo de que una cultura de paz es posible y deseable.

Una cultura de paz implica entonces que los actores sociales asuman de manera comprometida un modo de vida, en el cual puedan ejercer los principios básicos de la paz; tales como la participación ciudadana, el ejercicio de la libertad personal y colectiva, el respeto y reconocimiento de los demás y de sí mismos, la búsqueda de la justicia y una comunicación orientada al entendimiento con los demás (Proyecto Educación y Cultura de Paz, 2002). Involucra el entrar en un proceso de cambio en las estructuras de las personas que conforman la sociedad y de aquellas instituciones que la configuran y estructuran. Por otro lado, requiere que las formas de ser, sentir, pensar y actuar de las personas y la colectividad respondan a los principios de paz cada vez que se entre en contacto con el Otro, diferente a uno mismo.

Construir la paz requiere de la aplicación de dos estrategias: una de Investigación para la Paz, dirigida a diagnosticar la naturaleza e intensidad de las actitudes intergrupales, y otra, de Educación para la Paz, fundamentada en la primera y destinada a desarrollar en la poblaciónobjetivo las actitudes y conductas necesarias para la consolidación de una Cultura de Paz.

El diagnóstico de las actitudes puede efectuarse en las áreas intra o internacionales. El ámbito intranacional es abordado cuando se analizan los modos de pensar, sentir y actuar existentes entre grupos involucrados dentro de un país determinado. Alternativamente, en el ámbito internacional, la investigación se enfoca en el estudio de las actitudes entre países.

Las actitudes internacionales se desarrollan a partir de una experiencia histórica compartida y cambian a lo largo del tiempo 
(Boulding, 1959). Son producto de mensajes recibidos en el pasado que constituyen un capital de información altamente estructurado. Las impresiones sobre la nacionalidad se forman mayoritariamente en la niñez y en el grupo familiar. El sistema educativo y la propaganda refuerzan meramente las actitudes que se derivan esencialmente de la cultura familiar. Las actitudes pueden ser fácilmente pervertidas y configurar decisiones en materia de política internacional que influyen sobre millones de personas, para justificar monstruosas crueldades e iniquidades. Por ello resulta de suma importancia analizar transversal y longitudinalmente las actitudes que los tomadores de decisiones de una nación (Presidente, Ministro de Defensa, Ministro de RREE, el Jefe del Comando Conjunto, etc.) así como de profesiones tales como la docencia, que ejercen un claro efecto multiplicador en la población estudiantil de las imágenes de la propia nación y de las que integran su entorno internacional inmediato.

Los resultados de la investigación sobre actitudes internacionales puede sustentar productivamente el diseño de programas de Educación para la Paz destinados al mejoramiento de las actitudes entre grupos pertenecientes a distintos países que han mantenido una historia de interacciones conflictivas, con el fin de crear condiciones psicosociales favorables para la una cultura de paz, la cooperación internacional y el desarrollo humano compartido. basados en el criterio de una comunidad solidaria, democrática, participativa, de diálogo y respeto irrestricto por el otro.

Los programas educativos dirigidos a la construcción de una Cultura de Paz pueden ser facilitados u obstaculizados por las imágenes de la propia nación y de otras naciones que los diversos grupos intervinientes, tales como: líderes políticos, comunicadores sociales, docentes, padres de familia, alumnos, etc., puedan albergar en sus mentes y manifestarse en conductas cooperativas o conflictivas de diversas intensidades. Por ello resulta de especial importancia el analizar estas imágenes en los mencionados grupos en base a su definido efecto multiplicador de información en una sociedad determinada. 
En el presente estudio, el interés se centra en la evaluación de las imágenes de los países limítrofes en estudiantes de Educación, dado que, al ejercer la docencia en el futuro pueden difundir entre sus alumnos tanto imágenes favorables como desfavorables de los países vecinos y producir actitudes y conductas de cooperación o competencia, xenofilia o xenofobia con respecto a los mismos. Las actitudes internacionales cargadas de hostilidad pueden afectar los esfuerzos dirigidos a la Integración Latinoamericana y a la construcción de una Cultura de Paz entre las naciones.

Cuando se evalúan las actitudes que ostenta la población de un país como el Perú hacia los nacionales de diferentes países limítrofes (Ecuador, Colombia, Brasil, Chile y Bolivia), reviste una especial importancia el análisis de: a) las dimensiones actitudinales de: Cortesía, No Probabilidad de Guerra, Confiabilidad, Solidaridad y Cooperatividad atribuidas a cada país limítrofe y b) la influencia que sobre las dimensiones actitudinales mencionadas ejercen predictores específicos tales como: el Dogmatismo el Autoritarismo de Derecha $(R W A)$, la Orientación hacia la Dominación Social $(S D O)$, el Maquiavelismo $(M A Q)$, el Nacionalismo (NAC) y el Patriotismo (PAT).

El Dogmatismo (DOG), fue definido por Rokeach (1954) como: (a) un sistema cognitivo relativamente cerrado de creencias e incredulidades (belief and unbelief system) acerca de la realidad (b) organizado en torno de un conjunto central de creencias acerca de la autoridad absoluta, que a su vez, (c) provee un marco de referencia para pautas de intolerancia y de tolerancia calificada hacia los demás. Es entendido como un estilo cognitivo de mente cerrada que puede ser asociado, sin tener en cuenta el contenido, con cualquier ideología, con una visión autoritaria de la vida, con una intolerancia respecto a los que sostienen creencias opuestas y con una tolerancia hacia aquellos con creencias similares (Rokeach,1960). La mente cerrada puede ser observada en el mundo práctico de las creencias políticas y religiosas y en el mundo más académico del pensamiento científico, filosófico y humanístico.

La aplicación de la teoría al campo de las percepciones internacionales por Al Ganideh y Elahee (2014) permitió detectar una influencia 
significativa del dogmatismo en los sentimientos de animosidad que consumidores jordanos expresaron contra Estados Unidos y sus productos. En el mismo contexto, Guido et. al. (2010) concluyeron que el dogmatismo no tenía una influencia significativa sobre los sentimientos de animosidad de consumidores judíos italianos en contra de productos árabes. Por otro lado, Jones y Melcher (1982) sugirieron una asociación positiva entre el dogmatismo y una conducta internacional de tipo confrontacional.

El Autoritarismo de Derecha ( $R W A)$ describe una tendencia (Altemeyer,1998) a creer intensamente en la sumisión a autoridades establecidas y en las normas sociales que estas autoridades aprueban. Creen asimismo en agredir a cualquier blanco que estas autoridades señalen. Esta estructura de personalidad es observable en la edad adulta temprana y es mejor explicada mediante el aprendizaje social que por la teoría psicoanalítica y se desarrolla durante la adolescencia a partir de un entrenamiento temprano en la obediencia, el convencionalismo y la agresión, a medida que es modificada por las experiencias subsecuentes del individuo.

Las personas con altos puntajes en $R W A$ son impulsadas por el miedo y por la percepción de que el mundo es un lugar peligroso y amenazador (Altemeyer, 1998). Están especialmente inclinados a temer el ser atacados por otros y por ello son más proclives a comprometerse en violencia de masas o en actos de guerra o de terrorismo. Por lo tanto, el miedo y el odio hacia los demás puede invitar a altos RWA a perpetuar, más que a mitigar, los conflictos de grupo (Altemeyer, 1996). Mediante un juego de simulación, Altemeyer (2004) observó que los Altos RWA terminaban dicho juego dramáticamente en un holocausto nuclear que aniquiló a todo el mundo. Dada una segunda oportunidad, los jugadores produjeron una tragedia con hambruna, desastre y guerras convencionales aniquilando 2,100 millones de personas.

Adicionalmente se han registrado asociaciones entre Alto $R W A$ y variables tales como: (a) el Etnocentrismo en estudiantes canadienses (Altemeyer, 2003) (b) asociaciones positivas con el apoyo actitudinal al involucramiento de Estados Unidos en la Guerra de Vietnam 
(Altemeyer, 1996), y negativas con la participación en una moratoria protestando contra la guerra, (c) asociaciones positivas con las actitudes (Doty et. al. 1997) en favor de la guerra del Golfo Pérsico y del ataque a Irak (McFarland, 2005).

La Sumisión a la Autoridad es un factor común entre el $D O G$ y el $R W A$ y se requiere esclarecer si existe un proceso de reforzamiento mutuo que puede proporcionar un canal de expresión para actitudes y conductas agresivas hacia países limítrofes tales como la xenofobia o el belicismo que sean reforzadas a lo largo del proceso de socialización del niño y del adolescente, involucrando contenidos convencionales que desarrollen una percepción de estarse conduciendo en base a normas establecidas.

La Orientación hacia la Dominación Social $(S D O)$ se manifiesta como una tendencia a percibir la sociedad en términos jerárquicos, así como en un intenso deseo de que el propio grupo social domine y subyugue a otros grupos (Pratto et al., 1994). Se ha detectado una relación entre la $S D O$ y el respaldo a la utilización de la fuerza militar como medio de tratar con los conflictos internacionales (Altemeyer, 2003; Crowson, 2009a; Crowson, DeBacker, \& Thoma, 2006). Alexander et al. (2005) registraron una correlación significativa $(r=-.30)$ entre $S D O$ y la imagen de Barbarie de Estados Unidos en una muestra de población libanesa. Individuos con alta $S D O$ que desean sistemas sociales menos igualitarios pueden tener imágenes más positivas de naciones poderosas tales como Estados Unidos, como un modo de promover la estructura jerárquica de las relaciones internacionales. Por lo tanto, desde una perspectiva de SDO, el mantener imágenes específicas de exogrupos puede servir a los deseos individuales de dominación basada en el grupo.

La Ideología Conservadora (IC) se expresa en la relación entre las variables $R W A$ y SDO $(r=.22)$, que fue originalmente sugerida por Altemeyer (1998) que resultó responsable por el 50\% del prejuicio analizado. Carvacho (2010) consideró a RWA y SDO como actitudes ideológicas que muestran: (a) una cierta estabilidad a través de las sociedades aún bajo influencias moderadas (b) una fuerte predicción 
de actitudes hacia exogrupos. En estudios efectuados en poblaciones peruanas encontraron correlaciones de $.36, .34$ y de .26 entre ambas variables, respectivamente (Espinosa et al., 2016; Janos et al., 2018; Rottenbacher et al. 2011).

Por otro lado, Duckitt et al. (2002) subrayaron las diferencias entre ambos constructos. RWA es una respuesta al mundo como siendo peligroso y $S D O$ es una respuesta a la percepción del mundo como competitivo. El poder predictivo de la combinación de ambos constructos se demostró en aplicaciones en Chile y Alemania al medir actitudes hacia inmigrantes (Carvacho, 2010). Se requiere indagar la medida en la que las personas que ostenten altos puntajes de SDO favorecerán concomitantemente una actitud de mayor belicismo hacia los países limítrofes.

El Maquiavelismo $(M A Q)$ fue entendido por Christie et al. (1970) como: (a) una visión del mundo fría y cínica con creencias pragmáticas e inmorales, (b) Carencia de emocionalidad, (c) Planeamiento estratégico a largo plazo persiguiendo metas de beneficio propio y (d) Diversas conductas manipulatorias. Aunque no se han detectado estudios sobre el poder predictivo del $M A Q$ con respecto a imágenes internacionales, estimamos pertinente incluir su evaluación en la presente propuesta con el fin de establecer su covariación con las actitudes hacia países limítrofes con el Perú. Interesa explorar la posibilidad de que las personas con alto $M A Q$ tiendan a manipular a otros países en función del reforzamiento de la autoridad, la dominación social, la sumisión, y a los connacionales en función de la agresión al exogrupo bajo las formas de xenofobia y belicismo.

El Nacionalismo $(N A C)$ fue definido por Langman (2006) como un conjunto de creencias sobre los orígenes comunes, peculiaridad, destino y rituales y compromisos patrióticos, himnos y celebraciones que unen a la gente en una identidad, otorgando una comunidad política imaginada que crea ciudadanos y que considera al Estado como indispensable para el funcionamiento político, social, cultural y económico de la gente. 
Un intenso nacionalismo puede estar altamente relacionado con las anteriores variables, manipulando a sus connacionales para promover la sumisión a líderes nacionalistas, la conducta convencionalista, el predominio etnocéntrico de la propia nación sobre los demás países, la intolerancia, la xenofobia y el belicismo. Requiere distinguirse del Patriotismo, entendido como un apego afectivo hacia el endogrupo, implicando sentimientos de pertenencia, responsabilidad y orgullo y que. a diferencia del Nacionalismo, no incluye la visión del propio país como superior a los demás y que como tal debe ser dominante. y tampoco involucra la humillación del exogrupo Kosterman \& Feshbach, 1989).

Las Actitudes hacia Países Limítrofes con el Perú fueron evaluadas mediante una encuesta desarrollada en las ciudades de Lima y Tacna, (Ibánez, 2010) donde se detectó una actitud defensiva en lo militar y económico del Perú frente a Chile, que recibía la influencia directa del autoritarismo $(R W A)$, la saliencia subjetiva del conflicto, la valoración de los peruanos y una influencia inversa de la simpatía hacia los chilenos y la valoración de los mismos. La autora sugirió que la conjunción de estas cinco variables es necesaria para predecir en los individuos limeños y tacneños la presencia de una actitud suspicaz y defensiva frente a Chile. En el caso del revanchismo peruano, este recibe una influencia directa solo del $R W A$ e influencia inversa tanto de la simpatía por los chilenos como de la saliencia subjetiva del conflicto. En este sentido, la agresión autoritaria que expresa el $R W A$ puede estar influyendo sobre una actitud revanchista, más beligerante que la simple actitud defensiva o suspicaz.

En Tacna, a diferencia de Lima, se detectó una actitud suspicaz frente a Chile que parece estar ligada más a variables identitarias que al $R W A$, como en el caso de Lima (Ibáńez, 2010). Por otro lado, en caso del revanchismo peruano en Tacna, únicamente la valoración de los chilenos ejerce una influencia inversa sobre esta variable. En ambas ciudades las actitudes hostiles o defensivas hacia el vecino país parecen responder a procesos psicológicos, sociales e históricos significativamente distintos y bastante menos sencillos de lo que inicialmente se había propuesto (Ibáńez, 2010). 
En base a la evidencia recolectada hasta el momento sobre estos temas, proponemos el desarrollo de una investigación de tipo descriptivo y correlacional cuyo objetivo general es el de determinar la relación entre variables de estilo cognitivo, personalidad y actitudes sobre las actitudes hacia los países limítrofes con el Perú, y como objetivo específico, determinar la relación entre las variables: Dogmatismo, Autoritarismo de Derecha, Orientación hacia la Dominación Social, Maquiavelismo. Nacionalismo y Patriotismo con las percepciones de estudiantes de Educación sobre las actitudes hacia el Perú de los países limítrofes con el Perú (Ecuador, Colombia, Brasil, Chile y Bolivia) en las dimensiones de Cortesía, No Probabilidad de Guerra, Confiabilidad, Solidaridad y Cooperatividad-Conflictividad atribuidas a cada país limítrofe.

\section{Método}

\section{Participantes}

La muestra fue de tipo no probabilística. Participaron 409 estudiantes de dos Facultades de Educación pertenecientes a una Universidad Privada y a una Pública. Se eligió este tipo de población debido al efecto multiplicador que los docentes ejercen en una sociedad como transmisores de información sobre imágenes internacionales al alumnado a su cargo a través del proceso de la enseñanza. 159 estudiantes pertenecen a una Universidad Privada (UPR) y 250 a una Pública (UPU). En la UPR 23 (14.5\%) eran hombres y 126 (79.2\%) mujeres. Diez personas dejaron en blanco la pregunta sobre su sexo. En la UPU, 74 (29.6\%) eran hombres y 169 (67.6\%) mujeres. Siete personas dejaron en blanco la pregunta sobre su sexo. La edad promedio del grupo total fue de 22 ańos $(D E=3.00)$; la de los participantes de la UPR fue de 21.1 años $(D E=3.19)$. Los participantes de la UPU registraron una edad promedio de 22.6 ańos $(D E=3.00)$. 


\section{Medición}

Se utilizaron los siguientes instrumentos:

Ficha de Datos Sociodemográficos: Se recogieron datos sobre Sexo, Edad, Universidad y Año de Estudios (Apéndice B).

Escala de Dogmatismo (DOG) (Rokeach, 1960): Consta de 40 items y se propone clarificar y precisar el concepto del estilo cognitivo de la Mente Cerrada vs. la Mente Abierta .Para tal fin se propusieron características centrales del estilo cognitivo dogmático: a) el grado de apertura mental vs. la mente cerrada, b) la medida en la que el individuo cree en una sola visión correcta, c) la medida en la cual se rechaza ideas o puntos de vista que están en desacuerdo con la propia opinión y d) la ceguera o excesiva dependencia de la autoridad.(Ej.: Cuando se trata de diferencias de opinión en materia religiosa debemos cuidarnos de no transar con la posición contraria).Los ítems eran calificados con una escala Likert de cinco puntos que iban desde 1 :Completamente en desacuerdo a 5: Completamente de acuerdo. Se utilizó la traducción castellana efectuada por Cáceres (1971). En este estudio se analizó la confiabilidad de la forma E de 40 items de la Escala de Dogmatismo en una muestra de estudiantes universitarios, utilizando el método de confiabilidad por mitades $(r=.81)$ que se ubicaba entre los márgenes considerados aceptables de Rokeach entre .68 y .93. Todos los ítems registraron un alto poder discriminativo. Posteriormente, Benjdouis (1973) analizó el poder discriminativo la Escala en una muestra de trabajadores de la Reforma Educativa, obteniendo una $r=.83, p<.001 \mathrm{y}$ una confiabilidad de test-retest de .53 . Ambos autores concluyeron que la Forma E de la Escala no requería de ajustes para el medio peruano. En 1987, Altamirano (1987) calculó una confiabilidad por mitades de .78, considerada muy aceptable. Cabe señalar que en ninguno de los estudios citados se utilizó el alfa de Cronbach como medida de confiabilidad. En el presente estudio se obtuvo un alfa de Cronbach de .85.

Escala de Autoritarismo de Derecha ( $R W A)$ (Altemeyer, 1998) integrada por 23 ítems. Involucra tres factores: a) Sumisión ante la autoridad (Ej.: La obediencia y el respeto por la autoridad son las vir- 
tudes más importantes que un niño debe aprender). b) Agresión contra el exogrupo (Ej.: Ser benévolo con los vagos y criminales solo los animará a aprovecharse de nuestra debilidad, por lo que es mejor tener una mano dura cuando se trata con ellos). y c) Convencionalismo (Ej: Nuestras costumbres y herencia nacional son las cosas que nos han hecho grandes, y debería hacerse que ciertas personas muestren mayor respeto por ellas.) En una muestra de estudiantes chilenos, Cárdenas et al. (2009) encontraron un alfa de Cronbach de .86. Torabian y Abalakina (2012) registraron un alfa de Cronbach de .90 para una muestra de estudiantes americanos y otra de .85 en una muestra de estudiantes iraníes, y hallaron correlaciones significativas y positivas de .66 y .22 con actitudes favorables hacia la guerra en estudiantes norteamericanos e iraníes, respectivamente. La consistencia interna registrada en anteriores estudios en el medio peruano fluctúa entre .61 (Rottenbacher et al., 2011) y .85 (Espinosa et al., 2013) En el presente estudio se registró un alfa de Cronbach de .75 .

Escala de Dominación Social (SDO) (Sidanius \& Pratto, 1999): Contiene 16 items que miden la tendencia de un individuo a ver la sociedad en términos jerárquicos y a desear que el propio grupo social domine sobre otros. (Ej: Para conseguir lo que se quiere es a veces necesario usar la fuerza contra otros grupos) Se utilizó la traducción del psicólogo Álvaro González. Alexander et. al. (2005) registraron un alfa de Cronbach de .88 en una aplicación de la escala de SDO en una muestra de población libanesa. En una muestra de estudiantes chilenos, Cárdenas et al. (2010) registró un alfa de Cronbach de .86. La confiabilidad detectada en estudios peruanos va de .77 (Rottenbacher et al., 2011) hasta .90 (Janos et al., 2018). En el presente estudio se registró un alfa de Cronbach de .81 .

Escala de Maquiavelismo (MAQ) (Christie et. al, 1969): Se utilizó la versión Kiddie Mach, que incluye 20 items (Ej. A veces uno tiene que dañar a otra gente para conseguir lo que uno quiere). Cada ítem debía ser calificado mediante una escala Likert de 5 puntos, donde $5=$ Completamente de acuerdo y $1=$ Completamente en desacuerdo. Se utilizó la traducción de la escala al castellano efectuada por González et al. 
(2011), aplicando el instrumento en una muestra española obtuvieron un alfa de Cronbach de .70. Sin embargo en el presente estudio el valor obtenido fue de .63 , el cual estuvo por debajo del mínimo aceptable de .70. El análisis de ítems indicó que la eliminación de ningún ítem elevaba el alfa de Cronbach hasta el límite aceptable, por lo que se optó por no utilizar esta escala.

Escala de Patriotismo-Nacionalismo (PAT-NAC): Se utilizó la Escala de Patriotismo-Nacionalismo de Kosterman y Feshbach (1989), que consta de 20 items. Doce de ellos miden el Patriotismo (Ej: Siento un gran orgullo por ese país que es nuestro Perúl y ocho el Nacionalismo (Ej.: Generalmente, cuanto más influencia tiene el Perú sobre otras naciones. mejores se tornan esas naciones). Utiliza una escala Likert de 5 puntos. donde 5 = Completamente de acuerdo y $1=$ Completamente en desacuerdo. Analizando las actitudes de estudiantes de bachillerato italianos, Miglietta et al. (2018) registró un alfa de Cronbach de .60 para Nacionalismo y .86 para Patriotismo. Adicionalmente, Leite et al. (2018) detectó un alfa de Cronbach de .78 para Patriotismo en un grupo de estudiantes universitarios brasileños. Para el presente estudio se utilizó la traducción de la escala al castellano efectuada por el Psicólogo Alvaro González. Solo se encontró una confiabilidad aceptable en la escala de Patriotismo, con un alfa de Cronbach de .86, por lo que no se aplicó la escala de Nacionalismo $(\alpha=.64)$.

Diferencial Semántico $(D S)$ : Instrumento originalmente diseñado por Osgood et al. (1957) y modificado por Greene (citado por Mueller, 1969), para efectos de mediciones del significado connotativo de conceptos en relaciones internacionales. Incluye una versión de cinco escalas de siete puntos con anclajes en las que $1=$ corresponde al extremo Menos Deseable y 7 al Más Deseable. Las escalas miden las percepciones sobre los aspectos de: a) Cortesía, b) No Probabilidad de Guerra, c) Confiabilidad, d) Solidaridad y e) Cooperatividad-Conflictividad respecto a los cinco países limítrofes con el Perú: Chile, Ecuador, Colombia, Brasil y Bolivia. Permite: a) Efectuar comparaciones por escalas y por puntajes totales de significado connotativo entre las percepciones de los países mencionados y b) Analizar los Espacios Semánticos (ES) resultantes 
(Kerlinger, 1966) de las comparaciones entre las percepciones de cada país con cada otro de los restantes cuatro países, así como la correlación entre matrices de ES entre ambas universidades estudiadas.

\section{Procedimiento}

Para llevar a cabo la investigación se coordinaron acciones con los Decanos de las Facultades de Educación de la universidad privada (UPR) y de la pública (UPU) de Lima, quienes brindaron las facilidades para la recolección de los datos mediante la aplicación grupal de los cuestionarios a los alumnos de sus respectivas Facultades. Se informó a los alumnos que su participación era voluntaria y se pidió a aquellos que accedieron a responder los cuestionarios que leyeran y firmaran un consentimiento informado. Previamente a la aplicación de los cuestionarios se llevó a cabo un estudio piloto para evaluar el nivel de legibilidad e inteligibilidad de los cuestionarios. La recolección de datos se efectuó entre los meses de agosto y diciembre del 2018.

\section{Análisis de Datos}

Se analizó la información recolectada mediante el paquete estadístico SPSS versión 24. El procedimiento se inició con el análisis de normalidad, de asimetría y kurtosis y de confiabilidad de los instrumentos mediante el estadístico del Alfa de Cronbach. A continuación, se efectuó el análisis descriptivo de las variables de estudio comparando las respuestas provenientes de ambas Universidades y se diseñaron dispersigramas sobre la base de los resultados del Diferencial Semántico.

El siguiente paso consistió en el análisis correlacional entre las variables independientes de DOG, RWA, SDO y PAT entre sí y de las mencionadas variables independientes con las variables dependientes de: Cortesía, No Probabilidad de Guerra, Confianza, Solidaridad y Cooperatividad-Competitividad, para cada país limítrofe con el Perú. En la escala de No Probabilidad de Guerra, bajos puntajes corresponden a una alta probabilidad de guerra y altos puntajes,a una baja probabilidad de guerra. En la escala de Cooperatividad-Competitividad, 
altos puntajes corresponden a alta Cooperatividad y bajos puntajes a alta Competitividad. Seguidamente se efectuaron regresiones múltiples para las actitudes hacia cada país limítrofe respecto a las variables independientes arriba mencionadas.

Se procedió a continuación a calcular los Espacios Semánticos (ES) (Kerlinger, 1966) entre las percepciones de los cinco países, basándose en la premisa de que, cuanto más cercanos estén dos países en el ES, más similares serán en el significado desde el punto de vista del individuo o grupo que efectúan las evaluaciones. Por el contrario, si están separados en el ES, diferirán en significado. Con el fin de detectar conglomerados de las percepciones y la correlación entre las matrices de ES entre las percepciones de los participantes de ambas universidades relativas a los cinco países limítrofes respecto del Perú, se calcularon dichas distancias mediante la Fórmula que aparece en el Apéndice J.

Sobre la base de la información así obtenida se construyeron tres matrices de ES correspondientes a las muestras de participantes: 1) Total, 2) De la UPR y 3) De la UPU.

\section{Resultados}

\section{Datos Sociales}

Se muestran en primer lugar en la Tabla 1 los estadísticos descriptivos de la comparación por universidades entre las variables independientes. 
El Perú y sus vecinos: fundamentos para una cultura de paz / González Riesle

\section{Tabla 1}

Descriptivos y comparación de las variables independientes según Universidad

\begin{tabular}{|c|c|c|c|c|c|c|c|c|}
\hline \multirow{2}{*}{ Variables } & \multicolumn{2}{|c|}{$\mathrm{UPR}(n=159)$} & \multicolumn{2}{|c|}{$\mathrm{UPU}(n=250)$} & \multicolumn{2}{|c|}{ TOTAL $(n=409)$} & \multirow{2}{*}{$t$} & \multirow{2}{*}{$p$} \\
\hline & $M$ & $D E$ & $M$ & $D E$ & $M$ & $D E$ & & \\
\hline DOG & 2.93 & .39 & 3.10 & .37 & 3.03 & .39 & -4.24 & $<.01$ \\
\hline RWA & 2.79 & .44 & 2.95 & .36 & 2.89 & .40 & -3.98 & $<.01$ \\
\hline SDO & 2.04 & .53 & 2.18 & .51 & 2.12 & .52 & -2.66 & $<.05$ \\
\hline PAT & 3.75 & .57 & 3.80 & .55 & 3.78 & .56 & -.87 & .38 \\
\hline
\end{tabular}

Se aprecia en la Tabla 1 que los puntajes de DOG, SDO y RWA son significativamente mayores en la muestra de la Universidad Pública que en la de la Privada. En la UPR los promedios de DOG, RWA y $S D O$ se ubican ligeramente por debajo del punto medio de la escala (3). El PAT se ubica ligeramente por sobre dicho punto medio. En el caso de la muestra de la UPU, el $D O G$ y el $P A T$ se ubican por sobre el punto medio; y RWA y $S D O$, por debajo del mismo., Por otro lado, no se registran diferencias significativas en la variable de PAT, en la que los puntajes se ubican ligeramente por sobre el punto medio mencionado.

Se detectaron diferencias significativas entre las muestras de ambas universidades al efectuar la comparación entre Sexos de los puntajes SDO y PAT. El puntaje SDO obtenido fue significativamente mayor en Hombres que en Mujeres $(F=12.61, p<.05)$ (En UPR, Hombres: $M=2.45, D E=.45$; Mujeres: $M=1.96$ y $D E=.52$. En UPU, Hombres: $M=2.29, D E=.58$; Mujeres: $M=2.11, D E=.46$ ).

Asimismo, se detectaron diferencias significativas entre Sexos en la variable de PAT, en ambas instituciones, siendo mayor el puntaje obtenido por el grupo de Mujeres $(\mathrm{F}=7.16, \mathrm{p}<.05)$ (En UPR, Hombres: $M=3.51, D E=.45$; Mujeres: $M=3.79, D E=.60$. En UPU, Hombres: $M=3.66, D E=.63$; Mujeres: $M=3.88, D E=.51)$. 
Los tres niveles de Edades establecidos: (a) De 18 a 20 años, (b) de 21 a 23 años) y (c) de 24 años o más, no registraron diferencias significativas en las cuatro variables independientes comparadas. Las diferencias entre Años de Estudios (del Segundo al Quinto Año) tampoco fueron estadísticamente significativas en ambas instituciones.

\section{Actitudes hacia el Perú percibidas en los países limitrofes}

A continuación se muestra en la Tabla 2 el análisis descriptivo general de las variables de Actitudes hacia el Perú percibidas en los Países Limítrofes con el Perú (Colombia, Chile, Brasil, Ecuador y Bolivia).

\section{Tabla 2}

Descriptivos de las actitudes hacia el Perú que la Muestra Total percibe en los países limitrofes del Perú

\begin{tabular}{lccccccccccc}
\hline \multirow{2}{*}{ Países } & \multicolumn{1}{c}{ Cortesía } & \multicolumn{3}{c}{$\begin{array}{c}\text { No probabilidad } \\
\text { de guerra }\end{array}$} & Confianza & \multicolumn{2}{c}{ Solidaridad } & \multicolumn{2}{c}{$\begin{array}{c}\text { Cooperatividad- } \\
\text { Conflictividad }\end{array}$} \\
\cline { 2 - 12 } & $M$ & $D E$ & $M$ & $D E$ & $M$ & $D E$ & $M$ & $D E$ & $M$ & $D E$ \\
\hline Colombia & $\mathbf{4 . 9 6}$ & 1.03 & $\mathbf{4 . 6 7}$ & 1.22 & $\mathbf{4 . 6 1}$ & .99 & 4.98 & .86 & $\mathbf{4 . 8 2}$ & .83 \\
Chile & $\underline{\mathbf{3 . 3 6}}$ & 1.44 & $\underline{\mathbf{2 . 8 5}}$ & 1.39 & $\underline{\mathbf{3 . 0 6}}$ & 1.42 & $\underline{\mathbf{3 . 7 0}}$ & 1.41 & $\underline{\mathbf{3 . 2 4}}$ & 1.37 \\
Brasil & 5.07 & .98 & 4.59 & 1.28 & 4.57 & 1.05 & 4.94 & .91 & 4.77 & .87 \\
Ecuador & 4.81 & .90 & 4.24 & 1.24 & 4.53 & .96 & 4.89 & .89 & 4.73 & .86 \\
Bolivia & 4.80 & 1.03 & 4.46 & 1.29 & $\mathbf{4 . 6 1}$ & 1.00 & $\mathbf{5 . 0 2}$ & .92 & 4.79 & .92 \\
\hline$F$ & 170.15 & & 139.23 & & 156.98 & & 126.11 & & 193.27 & \\
\hline$p$ & .00 & & .00 & & .00 & & .00 & & .00 & \\
\hline
\end{tabular}

Nota. En negrita cursiva: Puntajes más altos. En negrita subrayada: Puntajes más bajos 


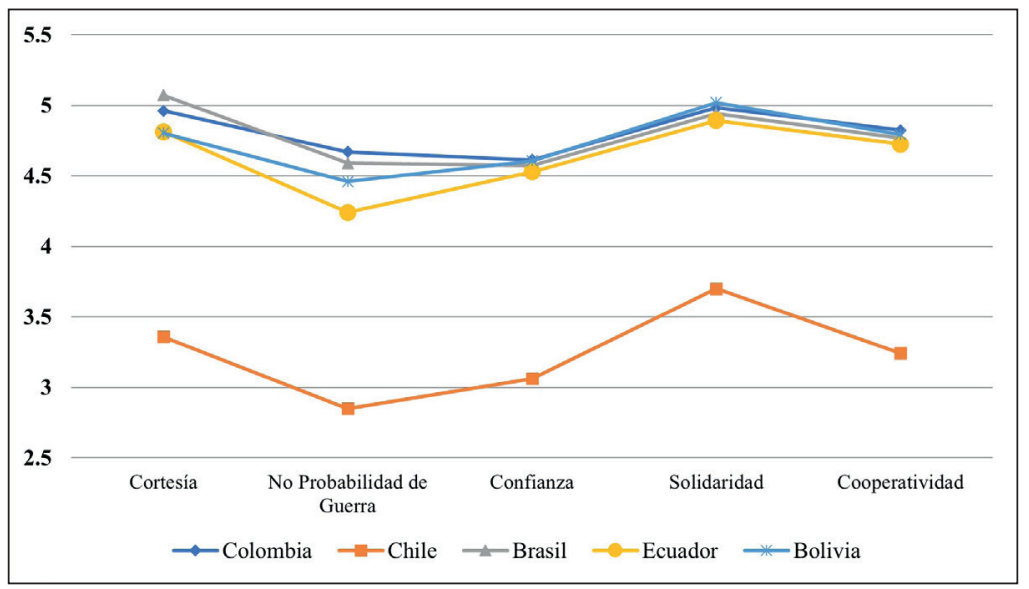

Figura 1. Actitudes que la Muestra Total percibe en los países limítrofes del Perú

En la Muestra Total, se registran diferencias altamente significativas en las cinco variables dependientes para los cuatro países limítrofes, Las percepciones más favorables sobre las actitudes de los cinco países limítrofes con el Perú se concentran en Colombia y las más desfavorables en Chile. En la variable de Solidaridad, Bolivia registra un puntaje más alto que Colombia y el mismo puntaje que Colombia en Confianza. Los puntajes de Colombia, Brasil, Ecuador y Bolivia de concentran por encima del punto medio de la escala de 7 puntos (4). Por el contrario, las percepciones sobre Chile se ubican por debajo de dicho punto medio. 


\section{Tabla 3}

Descriptivos de las actitudes hacia el Perú que los estudiantes de la muestra de la Universidad Privada perciben en los paises limitrofes

\begin{tabular}{lcccccccccc}
\hline \multirow{2}{*}{ Países } & \multicolumn{1}{c}{ Cortesía } & $\begin{array}{c}\text { No Probabilidad } \\
\text { de Guerra }\end{array}$ & Confianza & Solidaridad & $\begin{array}{c}\text { Cooperatividad. } \\
\text { Conflictividad }\end{array}$ \\
\cline { 2 - 11 } Colombia & 5.04 & 0.97 & $\mathbf{4 . 6 4}$ & 1.21 & 4.69 & 0.98 & $\mathbf{5 . 0 1}$ & .90 & $\mathbf{4 . 8 2}$ & .86 \\
Chile & $\underline{\mathbf{3 . 3 6}}$ & 1.46 & $\underline{\mathbf{2 . 9 9}}$ & 1.53 & $\underline{\mathbf{3 . 2 1}}$ & 1.46 & $\underline{\mathbf{3 . 8 8}}$ & 1.41 & $\underline{\mathbf{3 . 3 3}}$ & 1.50 \\
Brasil & $\mathbf{5 . 1 9}$ & .98 & $\mathbf{4 . 6 4}$ & 1.32 & $\mathbf{4 . 7 1}$ & 1.00 & 4.93 & .90 & 4.76 & 0.87 \\
Ecuador & 4.89 & .86 & 4.27 & 1.32 & 4.67 & .85 & 4.88 & .83 & 4.76 & .86 \\
Bolivia & 4.72 & .95 & 4.38 & 1.30 & 4.67 & .90 & 4.89 & .86 & 4.72 & .96 \\
\hline$F$ & 75.50 & & 41.95 & & 61.47 & & 35.59 & & 60.69 & \\
\hline$p$ & .00 & & .00 & & .00 & & .00 & & .00 & \\
\hline
\end{tabular}

Nota. Con negrita cursiva: puntajes más altos. En negrita subrayada: puntajes más bajos

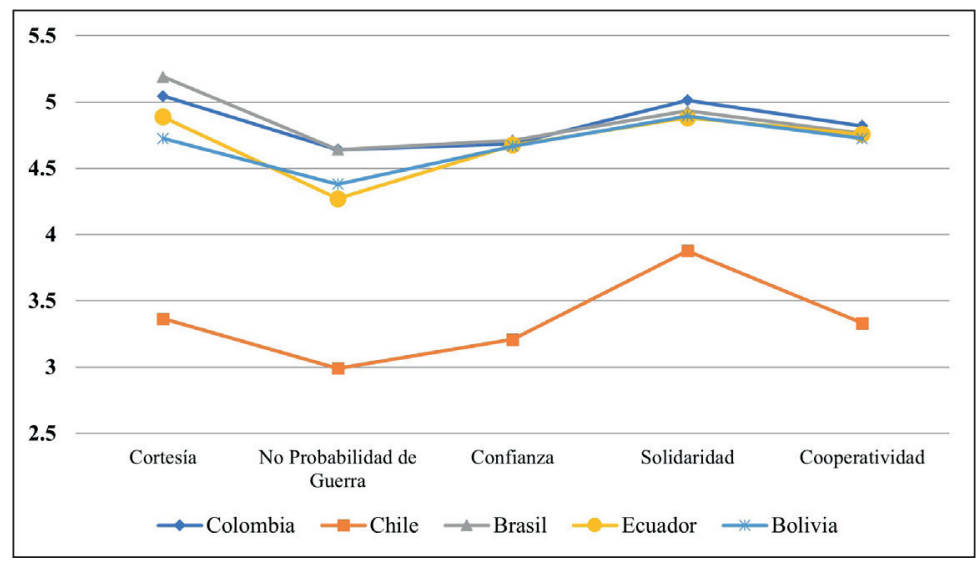

Figura 2. Actitudes que los estudiantes de la muestra de la Universidad Privada perciben en los países limítrofes del Perú. 
Los respondentes de la Universidad Privada registran percepciones más favorables hacia Colombia en las variables de: Probabilidad de Guerra, Solidaridad y Cooperatividad; y hacia Brasil en Cortesía, Probabilidad de Guerra y Confianza. La concentración de puntajes es similar a la de la Figura 1.

\section{Tabla 4}

Descriptivos de las actitudes hacia el Perú que los estudiantes de la muestra de la Universidad Pública perciben en los paises limitrofes

\begin{tabular}{lccccccccccc}
\hline \multirow{2}{*}{ Países } & \multicolumn{9}{c}{ Cortesía } & \multicolumn{3}{c}{$\begin{array}{c}\text { No Probabilidad } \\
\text { de Guerra }\end{array}$} & Confianza & \multicolumn{2}{c}{ Solidaridad } & \multicolumn{2}{c}{ Cooperatividad- } \\
\cline { 2 - 12 } & $M$ & $D E$ & $M$ & $D E$ & $M$ & $D E$ & $M$ & $D E$ & $M$ & $D E$ \\
\hline Colombia & 4.91 & 1.07 & $\mathbf{4 . 7 0}$ & 1.23 & $\mathbf{4 . 5 7}$ & 1.00 & 4.96 & .84 & 4.83 & .82 \\
Chile & $\underline{\mathbf{3 . 3 6}}$ & 1.43 & $\underline{\mathbf{2 . 7 7}}$ & 1.29 & $\underline{\mathbf{2 . 9 7}}$ & 1.39 & $\underline{\mathbf{3 . 5 9}}$ & 1.40 & $\underline{\mathbf{3 . 1 9}}$ & 1.29 \\
Brasil & $\mathbf{5 . 0 0}$ & .97 & 4.57 & 1.26 & 4.49 & 1.08 & 4.94 & .91 & 4.77 & .87 \\
Ecuador & 4.77 & .91 & 4.23 & 1.19 & 4.44 & 1.01 & 4.90 & .93 & 4.71 & .86 \\
Bolivia & 4.86 & 1.07 & 4.51 & 1.28 & $\mathbf{4 . 5 7}$ & 1.05 & $\mathbf{5 . 1 0}$ & .94 & $\mathbf{4 . 8 4}$ & .89 \\
\hline$F$ & 96.79 & & 99.97 & & 96.67 & & 93.33 & & 139.10 & \\
\hline$p$ & .00 & & .00 & & .00 & & .00 & & .00 & \\
\hline
\end{tabular}

Nota. Con negrita cursiva: puntajes más altos. En negrita subrayada: puntajes más bajos 


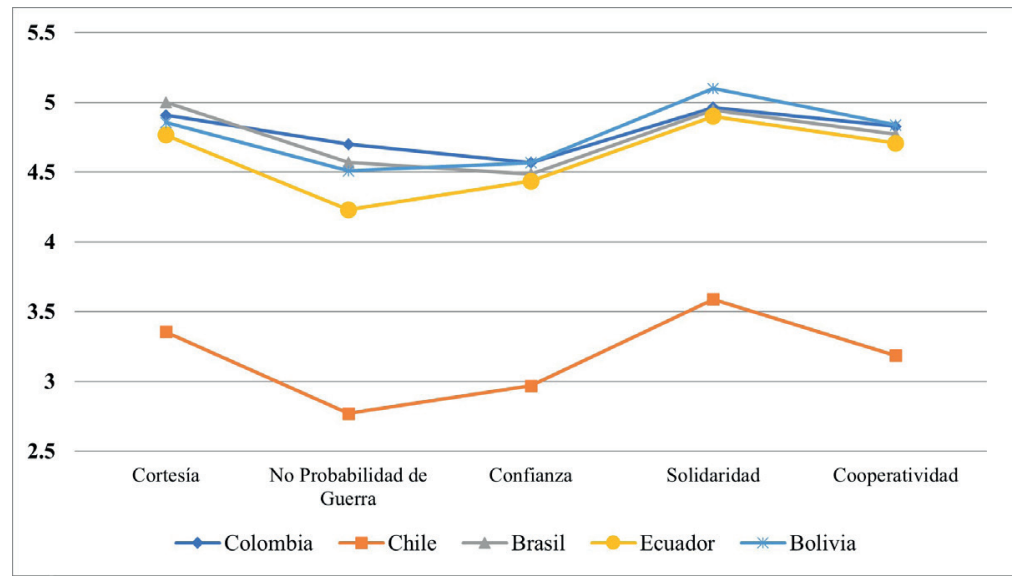

Figura 3. Actitudes que los estudiantes de la muestra de la Universidad Pública perciben en los Paises Limitrofes del Perú

En la muestra de la Universidad Pública, Colombia registra los puntajes más favorables en las variables de No Probabilidad de Guerra y Confianza. Las percepciones de Cortesía son las más altas en el caso de Brasil. Bolivia ostenta el mismo puntaje de Colombia en materia de Confianza y registra los puntajes más altos en Solidaridad y Compettividad. La concentración de puntajes es similar a la de la Figura 1.

\section{Correlaciones y Regresiones}

Se registra en la Tabla 5 una correlación baja $(r=.21 ; p<.001)$ entre los componentes del Conservadurismo ( $R W A$ y $S D O)$. A ello se agregan correlaciones significativas de ambas variables con el $D O G(.32$ y .14, respectivamente). El PAT se relaciona en forma inversa, moderada y significativa con $S D O(r=-.34)$ y en grado bajo pero directa y significativamente con $R W A(r=.32)$. Con el $D O G$ la relación es baja y no significativa. 
El Perú y sus vecinos: fundamentos para una cultura de paz / González Riesle

\section{Tabla 5}

Correlaciones entre las Variables Independientes: DOG, RWA, SDO y PAT

\begin{tabular}{lcccc}
\hline & 1 & 2 & 3 & 4 \\
\hline 1. DOG & - & & & \\
2. RWA & $.32^{* * *}$ & - & & \\
3. SDO & $.14^{* *}$ & $.21^{* * *}$ & - & \\
4. PAT & .01 & $11^{*}$ & $-.34^{* * *}$ & - \\
${ }^{*} p<.05 ;{ }^{* *} p<.01 ;{ }^{* * *} p<.001$ & & &
\end{tabular}

El PAT (Tabla 6) registra una correlación significativa pero baja con Cortesía y Solidaridad en el caso de Colombia.

\section{Tabla 6}

Correlaciones entre IC, PAT y Actitudes hacia Colombia

\begin{tabular}{lccccc}
\hline & Cortesía & $\begin{array}{c}\text { No Probabilidad } \\
\text { de Guerra }\end{array}$ & Confianza & Solidaridad & Cooperatividad \\
\hline DOG & -.04 & -.04 & -.09 & -.02 & -.05 \\
RWA & -.09 & .01 & -.09 & -.01 & -.03 \\
SDO & -.08 & .02 & -.02 & .04 & .07 \\
PAT & $.12^{*}$ & -.09 & .02 & $.12^{*}$ & .09 \\
\hline
\end{tabular}

${ }^{*} p<.05 ;{ }^{* *} p<.01 ;{ }^{* * *} p<.001$

En lo referente a la percepción de la actitud de Chile hacia el Perú (Tabla 7) el $D O G$ se relaciona inversa y significativamente con la Cortesía, la Confianza y la Cooperatividad y directamente en lo referente a la No Probabilidad de Guerra. Adicionalmente, el $R W A$ registra relaciones inversas con No Probabilidad de Guerra, Confianza, Solidaridad y Cooperatividad en el caso de Chile. 


\section{Tabla 7}

Correlaciones entre IC, PAT y Actitudes percibidas en Chile

\begin{tabular}{lccccc}
\hline & Cortesía & $\begin{array}{c}\text { No Probabilidad } \\
\text { de Guerra }\end{array}$ & Confianza & Solidaridad & Cooperatividad \\
\hline DOG & $-.10^{*}$ & $.16^{* *}$ & $-.17^{* *}$ & -.09 & $-.13^{* *}$ \\
RWA & -.03 & $-.14^{* *}$ & $-.18^{* *}$ & $-.13^{*}$ & $-.10^{*}$ \\
SDO & -.09 & .03 & -.06 & -.09 & -.04 \\
PAT & .08 & .05 & -.04 & .05 & .02 \\
\hline
\end{tabular}

${ }^{*} p<.05 ;{ }^{* *} p<.01 ;{ }^{* * *} p<.001$

Las percepciones sobre Brasil (Tabla 8) sugieren únicamente una relacion positiva entre $P A T$, por un lado y Cortesía y Confianza por el otro.

\section{Tabla 8}

Correlaciones entre IC, PAT y Actitudes percibidas en Brasil

Cortesía $\begin{gathered}\text { No Probabilidad } \\ \text { de Guerra }\end{gathered}$ Confianza Solidaridad Cooperatividad

\begin{tabular}{lccccc}
\hline DOG & -.02 & .05 & -.05 & -.01 & -.04 \\
RWA & -.07 & -.08 & -.00 & -.03 & .02 \\
SDO & -.08 & .07 & -.05 & .00 & .06 \\
PAT & $.20^{* *}$ & -.08 & $.10^{*}$ & .08 & .07 \\
\hline
\end{tabular}

${ }^{*} p<.05 ;{ }^{* *} p<.01 ;{ }^{* * *} p<.001$

En el caso de Ecuador (Tabla 9) se observa una relación significativa entre $D O G$ y No Probabilidad de Guerra, por un lado y entre PAT y Cortesía, por el otro. 
El Perú y sus vecinos: fundamentos para una cultura de paz / González Riesle

\section{Tabla 9}

Correlaciones entre IC, PAT y Actitudes percibidas en Ecuador

Cortesía $\begin{gathered}\text { No Probabilidad } \\ \text { de Guerra }\end{gathered}$ Confianza Solidaridad Cooperatividad

\begin{tabular}{llllll}
\hline DOG & -.06 & $.11^{*}$ & -.08 & -.07 & -.08 \\
RWA & -.08 & .00 & -.06 & -.09 & -.06 \\
SDO & -.07 & .06 & .01 & .02 & .03 \\
PAT & $.19^{* *}$ & -.05 & .04 & .09 & .10 \\
\hline${ }^{*} p<.05 ;{ }^{* *} p<.01 ;{ }^{* * *} p<.001$ & & &
\end{tabular}

En la Tabla 10 se observa una correlación baja, directa y significativa entre $S D O$ y Probabilidad de Guerra. El PAT registra correlaciones positivas, bajas y significativas con Cortesía, Confianza, Solidaridad y Cooperatividad y una correlación inversa y significativa con No Probabilidad de Guerra.

Tabla 10

Correlaciones entre IC, PAT y Actitudes percibidas en Bolivia

Cortesía $\begin{gathered}\text { No Probabilidad } \\ \text { de Guerra }\end{gathered}$ Confianza Solidaridad Cooperatividad

\begin{tabular}{lccccc}
\hline DOG & .02 & -.02 & -.05 & .00 & -.04 \\
RWA & .07 & -.01 & -.07 & -.05 & -.03 \\
SDO & -.03 & $.12^{*}$ & -.07 & .02 & .00 \\
PAT & $.12^{*}$ & $-.15^{* *}$ & $.15^{* *}$ & $.14^{* *}$ & $.12^{*}$ \\
\hline${ }^{*} p<.05 ;{ }^{* *} p<.01 ;{ }^{* * *} p<.001$ & & &
\end{tabular}

Se detectaron diferencias significativas entre ambos sexos en las variables de SDO y PAT, lo cual sugirió la necesidad de efectuar un análisis pormenorizado de dichas diferencias. Se calcularon promedios de los coeficientes de correlaciones para los puntajes correspondientes a las actitudes hacia el Perú percibidas en los cinco países limítrofes. 
En lo referente al SDO dichos promedios de correlaciones son mínimos (Apéndice K)

El SDO en el grupo de Hombres registra una relación inversa y figura como mejor predictor de las actitudes percibidas en Chile hacia el Perú en los aspectos de: Cortesía $\left(r=.24^{*}\right)$ Confiabilidad $\left(r=-24^{*}\right)$, Solidaridad $\left(r=-38^{* *}\right)$ y Cooperatividad $\left(r=-.25^{*}\right)$. Asimismo, figura como mejor predictor de la actitud de No Probabilidad de Guerra ( $r=-$ $\left..22^{*}\right)$ en el caso de Ecuador. No se registran relaciones significativas en el grupo de Mujeres.

El PAT en el grupo de Hombres registra una relación directa y figura como mejor predictor de la No Probabilidad de Guerra con Brasil $\left(r=.35^{* *}\right)$ y de Solidaridad con Chile $\left(r=.24^{*}\right)$. En el grupo de Mujeres, figura como mejor predictor de tres actitudes percibidas en Bolivia: No Probabilidad de Guerra $\left(r=.17^{* *}\right)$, Confiabilidad $\left(r=.18^{* *}\right)$ y Solidaridad $\left(r=.14^{*}\right)$. Asimismo, el PAT figura como mejor predictor de la Cortesía percibida en Brasil $\left(r=.21^{* *}\right)$ y la Cooperatividad en Ecuador $\left(r=.17^{* *}\right)$.

\section{Regresiones}

Al realizar el análisis de regresión mediante el Método INTRODUCIR las cuatro variables independientes (DOG, RWA, SDO y $P A T$ ) respecto a las variables dependientes (Actitudes percibidas en Colombia, Chile, Brasil, Ecuador y Bolivia), ninguna regresión resultó significativa. Para los cinco países, las cifras máximas obtenidas fueron las siguientes: $\mathrm{R}=.27 ; \mathrm{R}^{2}=.03$; $\mathrm{R}$ Ajustada $=.04$. Por ello, no se logró estructurar un modelo predictivo con las cuatro variables independientes evaluadas debido a lo exiguo tanto de la varianza compartida como del consiguiente valor predictivo de los modelos computados.

\section{Espacios Semánticos}

Los hallazgos referentes a los Espacios Semánticos $(E S)$ en la Muestra Total que aparecen en la Tabla 11 evidencian que los menores ES referentes a las percepciones de las relaciones con el Perú de los países limítrofes se agrupan por similitud en los bloques integrados por: 
1) Colombia, Brasil, Ecuador y Bolivia, por un lado, y 2) Chile, por el otro. Los mayores ES se observan entre: 1) Colombia y Chile (3.52); 2) Brasil y Chile (3.48); 3) Bolivia y Chile (3.35) y 4) Ecuador y Chile (3.14). Las menores, entre: 1) Colombia y Ecuador (.48); 2) Brasil y Ecuador (.44); 3) Brasil y Bolivia (.31); 4) Colombia y Bolivia (.27); y Ecuador y Bolivia (.27).

\section{Tabla 11}

Espacios semánticos entre Paises - Muestra Total

\begin{tabular}{lccccc}
\hline & Colombia & Chile & Brasil & Ecuador & Bolivia \\
\hline Colombia & - & 3.52 & $.16^{*}$ & $.48^{*}$ & $.27^{*}$ \\
Chile & - & - & 3.48 & 3.14 & 3.35 \\
Brasil & - & - & - & $.44^{*}$ & $.31^{*}$ \\
Ecuador & - & - & - & - & $.27^{*}$ \\
Bolivia & - & - & - & - & - \\
\hline
\end{tabular}

*Menores ES

Los resultados del análisis de los $E S$ por cada Universidad aparecen en las Tablas 12 y 13. Se calculó un coeficiente de correlación entre los casilleros homólogos de ambas tablas y se encontró un $r=.99$ lo que denota un alto grado de similitud entre los ES de los grupos de estudiantes de ambas universidades.

\section{Tabla 12}

Espacios semánticos entre Paises - Muestra UPR

\begin{tabular}{lccccc}
\hline & Colombia & Chile & Brasil & Ecuador & Bolivia \\
\hline Colombia & - & 3.35 & $.18^{*}$ & $.42^{*}$ & $.44^{*}$ \\
Chile & - & - & 3.39 & 3.03 & 2.98 \\
Brasil & - & - & - & $.48^{*}$ & $.54^{*}$ \\
Ecuador & - & - & - & - & $.21^{*}$ \\
Bolivia & - & - & - & - & - \\
\hline
\end{tabular}

*Menores ES 


\section{Tabla 13}

Espacios semánticos entre Paises - Muestra UPU

\begin{tabular}{lccccc}
\hline & Colombia & Chile & Brasil & Ecuador & Bolivia \\
\hline Colombia & - & 3.64 & $.19^{*}$ & $.52^{*}$ & $.24^{*}$ \\
Chile & - & - & 3.54 & 3.21 & 3.21 \\
Brasil & - & - & - & $.24^{*}$ & $.25^{*}$ \\
Ecuador & - & - & - & - & $.40^{*}$ \\
Bolivia & - & - & - & - & - \\
\hline
\end{tabular}

*Menores ES

Al comparar las matrices de ES de las muestras de la UPR y la UPU se detecta que la mayor discrepancia entre matrices se ubica en las diadas de: Colombia y Chile $=.29$ y Brasil- Bolivia $=+.29$. La menor discrepancia se ubica entre Colombia y Brasil= .01.

\section{Discusión}

El valor admonitorio de la teoría de la imagen de Boulding (1959) se evidencia en el enunciado de dicha teoría que afirma que la conducta no es producida por la realidad sino por la imagen que tenemos de la realidad, señalando la importancia que reviste la transmisión de la naturaleza de las imágenes del propio país y de los países limítrofes que los futuros maestros que integran las muestras analizadas puedan difundir entre sus educandos mediante sus exposiciones de clase, asignación de lecturas de textos históricos y discursos en la celebración de efemérides.

El contenido diferencial de esas imágenes puede conducir a conductas cooperativas o conflictivas. Cuanto más se intensifique una percepción de amenaza respecto a otro país y cuanto más se perciba a la otra nación como inamistosa. agresiva, desconfiable, insolidaria y competitiva, menores serán las probabilidades de instaurar una Cultura de Paz y mayores las probabilidades de incubación de futuros conflictos. 
En lo referente a los hallazgos específicos, la evidencia recolectada corrobora solo parcialmente la hipótesis planteada. Las variables independientes de: DOG, RWA, SDO y PAT no registran relaciones de igual intensidad ni integran un modelo significativo de regresión. con las cinco variables dependientes vinculadas con las actitudes hacia el Perú percibidas en los cinco países limítrofes.

En el caso de las percepciones vinculadas con Chile, en un nivel más preciso de análisis se observa que el $D O G$ se relaciona negativa y significativamente con Cortesía (-.10), Confianza (-.17) y Cooperatividad (-.13). Adicionalmente, el $R W A$ se relaciona negativa y significativamente con No Probabilidad de Guerra (-.13), Confianza (-.18), Solidaridad (-.13) y Cooperatividad (-.10).

El $R W A$ registra una correlación más alta y significativa que el $S D O$ con las percepciones relativas a la No Probabilidad de Guerra con Chile, lo cual sugiere que una tendencia a creer intensamente en la sumisión a autoridades establecidas y en las normas sociales que estas aprueban y una disposición a agredir a cualquier blanco que estas autoridades señalen, expresadas en el $R W A$,pueden ser mejores predictores de la percepciones de No Probabilidad de Guerra de Chile hacia el Perú. Ello corrobora los hallazgos de Ibáñez (2010) obtenidos en el análisis la población de Tacna.

El PAT registra relaciones significativas con las percepciones sobre: 1) Cortesía y Solidaridad en el caso de Colombia, 2) Cortesía y Confianza en el caso de Brasil 3) Cortesía en el caso de Ecuador. 3) Cortesía, No Probabilidad de Guerra, Confianza, Solidaridad y CooperatividadConflictividad en el caso de Bolivia. Ninguna de las correlaciones del PAT con las percepciones relativas a Chile son significativas. Estos hallazgos parecen sugerir que el $P A T$ es mejor predictor de aquellas percepciones vinculadas con un país como Bolivia con la que el Perú mantiene mayores similitudes históricas, culturales y raciales y menos eficaz predictor en relación con las de un país como Chile con el que ha mantenido una trayectoria cargada de conflictos.

Se corroboran los hallazgos de anteriores investigaciones sobre la Ideología Conservadora al observar una correlación positiva y 
significativa (.21) entre sus componentes (RWA y SDO). Sin embargo, la relación observada es menor a las registradas en los estudios de Rottenbacher, (2012), Rottenbacher y Schmitz (2012) y Espinosa et. al (2016).

El PAT se relaciona en forma opuesta con los componentes de la Ideología Conservadora. Muestra una correlación inversa, moderada y significativa con $S D O(-.34)$ y una directa y significativa con $R W A$ (.32). Es posible que el $R W A$ y el PAT compartan componentes, si se considera que el $R W A$ involucra la sumisión a la autoridad y las normas establecidas; y si incluimos en el PAT como normas el apego afectivo hacia el endogrupo, y la responsabilidad por su destino y el orgullo de pertenencia al propio país.

La relación inversa PAT-SDO puede vincularse con la no inclusión en la definición de Patriotismo de una relación jerárquica o hegemónica del propio país con los demás países, lo cual constituye una característica inherente al $S D O$, que contiene una visión competitiva del mundo y se relaciona con una mayor proclividad a utilizar la fuerza militar para resolver conflictos de diversa índole.

Adicionalmente, se registran las r's significativas de DOG con $R W A$ (.32) y con $S D O(.24)$. Teniendo en cuenta que ambas variables tienen como factor común la Sumisión a la Autoridad, se sugiere la posibilidad de continuar poniendo a prueba al $D O G$ como un nuevo componente de la Ideología Conservadora en futuras investigaciones.

El análisis descriptivo de las variables independientes de $D O G$, $R W A$ y $S D O$ registraron puntajes significativamente mayores en la muestra de estudiantes de Educación de la UPU en comparación con la proveniente de la UPR. No se observaron diferencias significativas en materia de PAT entre ambos grupos estudiados. El hallazgo anotado plantea el problema de establecer si los determinantes de estas diferencias se encuentran en factores tales como el clima organizacional, los contenidos y metodología de los cursos, el estilo de liderazgo docente, etc. de las dos Facultades de Educación estudiadas.

Las actitudes hacia el Perú percibidas en cuatro de los cinco países limítrofes (Colombia, Brasil, Ecuador y Bolivia) se acumulan más cerca 
del polo favorable de las cinco variables de: Cortesía, No Probabilidad de Guerra, Confianza, Solidaridad y Cooperatividad-Competitividad. Por el contrario, las percepciones sobre las actitudes de Chile hacia el Perú se concentran más cerca del polo desfavorable y por debajo de 4, que constituye el punto medio de las escalas de 7 puntos del Diferencial Semántico. En este país se percibe una mayor intensidad de niveles bajos en las percepciones de: Cortesía. Confianza, Solidaridad y Cooperatividad, y mayor Probabilidad de Guerra respecto al Perú. Estos hallazgos se corroboran con los resultados de un análisis de contenido de blogs intercambiados entre emisores peruanos y chilenos (González, 2014) donde se configura en los emisores peruanos una percepción de amenaza respecto a Chile, expresada en: a) Desconfianza: Frente a Chile hay que mantener siempre una actitud de prevención y alerta; b) Competitividad: Calificando a Chile como país: Usurpador, invasivo mediante la punta de lanza de sus inversiones, enemigo natural y geopolitico del Perú, el peor enemigo de un peruano es un chileno y c) Probabilidad de Guerra: viendo a Chile como: Potencia militar hegemónica y armamentista .

A ello se agregan los resultados de una encuesta en universitarios chilenos (Zambrano et. al., 2017), quienes consideraron a sus connacionales como más competitivos $(p<.001)$ y más agresivos $(p<.010)$ que los peruanos. Esta estructura actitudinal puede dificultar la consolidación de una estrategia de cooperación internacional y de una Cultura de Paz entre Perú y Chile. En comparación con los restantes cuatro países, los estudiantes de ambas universidades perciben en Colombia. mayor Cortesía, Confianza y Cooperatividad y menor Probabilidad de Guerra hacia el Perú.

En base a la noción de que las menores distancias semánticas entre las actitudes hacia el Perú percibidas por los estudiantes expresan una mayor cercanía entre países en materia de significado, se define la existencia de dos bloques integrados por: a) Colombia, Brasil, Ecuador y Bolivia, por un lado y b) Chile, por el otro.

Al comparar los ES de Chile con los otros cuatro países se detecta que el mayor ES se da con Colombia (3.52) y el menor, con Ecuador (3.14). Esta percepción de cercanía entre Chile y Ecuador puede estar 
relacionada con el recuerdo de la colaboración (ej: venta de armas) que se llevó a cabo entre ambos países durante el conflicto Perú-Ecuador. En este mismo análisis se observa que el ES Chile- Bolivia (3.35) no es mayor que el máximo ES registrado con Colombia. Considerando que se ha producido un diferendo entre ambos países relativo a la negociación sobre una salida al mar para Bolivia y que fue dirimido por el Tribunal de La Haya y los desencuentros históricos del pasado y el presente, se esperaría que la disimilitud fuera mayor. Se trata de un hallazgo contraintuitivo que requeriría una investigación más pormenorizada en el futuro.

En general, se observa en las muestras estudiadas que el peso de una historia conflictiva se refleja especialmente en las actitudes hacia Chile y señala la necesidad de priorizar la instauración de una Cultura de Paz y de una Integración Fronteriza en la interacción Perú-Chile.

\section{Limitaciones}

Las limitaciones del presente estudio se expresan en la no representatividad de la muestra analizada en relación con la población general de estudiantes de Educación peruanos. A ello se agrega la dificultad de distinguir entre el dogmatismo religioso y el político en instrumentos como la Escala de $D O G$, lo que permitiría efectuar una comparación más fina entre los resultados de universidades privadas confesionales y universidades públicas laicas. Las escalas de $M A Q$ y $N A C$ no alcanzaron el requerido nivel de confiabilidad, lo cual señala la necesidad de desarrollar versiones indígenas de estos instrumentos. Adicionalmente, no se ha explorado la posible influencia que la deseabilidad social vinculada con la experiencia histórica pueda ejercer en las percepciones relacionadas con Chile referentes a las actitudes de este país respecto al Perú.

\section{Recomendaciones}

La evidencia recolectada en la presente investigación señala las necesidades de: (a) Promover un abordaje investigatorio y pedagógico multidisciplinario para el análisis y solución de la problemática de las 
relaciones del Perú con sus países limítrofes. (b) Continuar incrementando mediante la Investigación para la Paz el corpus de conocimiento psicosocial que contribuya a fundamentar científicamente el diseño de estrategias dirigidas a la construcción de una Cultura de Paz entre los países arriba involucrados y (c) Diseñar estrategias de Educación para la Paz a insertarse en la formación de educadores peruanos.

\section{a. Investigación para la Paz}

Se recomiendan las siguientes actividades:

i. Integrar grupos multinacionales e interdisciplinarios de investigadores en las áreas de Educación para la Paz, Psicología Social del Conflicto y Comunicación para la Paz encargados de producir el conocimiento de base requerido para fundamentar el diseño de Estrategias de Educación para la Paz.

ii. Analizar en futuros estudios los efectos diferenciales que el estilo cognitivo del dogmatismo, la socialización política, el liderazgo autoritario, la visión jerarquizada de la sociedad, el nacionalismo y el patriotismo, la xenofobia y la comunicación social pueden ejercer sobre el desarrollo de imágenes mutuas entre Perú y los países limítrofes.

iii. Crear y perfeccionar instrumentos indígenas de evaluación de las variables arriba mencionadas con el fin de elevar la adecuación, confiabilidad y validez de dichos instrumentos.

iv. Continuar incluyendo el $D O G$ como variable independiente en futuros estudios de actitudes internacionales con el fin de estudiar sus posibilidades de incluirlo dentro de la Ideología Conservadora junto con el $R W A$ y $S D O$,

v. Aplicar el análisis factorial a los nuevos instrumentos utilizarse, con el fin de trabajar con criterios más precisos de análisis.

vi. Explorar las características existentes en los contenidos de los cursos, en la metodología de la enseñanza o en el clima organizacional de las Facultades de Educación de ambas universidades estudiadas que podrían influir en las diferen- 
cias detectadas en las variables de $D O G, R W A$, y $S D O$ y en la no detección de diferencias en la variable de $P A T$.

\section{b. Educación para la Paz}

Se proponen los siguientes objetivos educacionales (Psychologists for Social Responsibility,2003) generales: (a) Aplicar estrategias de Educación para la Paz para la formación de docentes como Agentes de Paz, dirigidas a la consolidación de una Cultura de Paz entre el Perú y sus países limítrofes,(b) Priorizar la aplicación de una estrategia de Educación para la Paz en el área de las relaciones Perú-Chile, en base a la necesidad de superar su historia de interacciones conflictivas. El ámbito de aplicación serían las Facultades de Educación y los Institutos Pedagógicos del Perú y de los países circundantes.

Para tal efecto, resulta de especial importancia el cabal conocimiento y comprensión no solamente de la historia de las relaciones del Perú con sus países vecinos sino también de la trayectoria sociocultural de los mismos con énfasis en los aportes de sus figuras señeras así como de los logros sociales y culturales de sus respectivos pueblos. Pueden incluirse temas tales como los de Cultura de Paz y Cultura de la Violencia, Desarrollo Humano, Interculturalidad y Sostenibilidad, Etica y Derechos Humanos, Desarme e Integración Latinoamericana y Fronteriza.

A ello se agrega la necesidad del desarrollo de habilidades de pensamiento crítico aplicado a: (a) la reducción de estructuras cognitivas tales como: dogmatismo, estereotipias y prejuicios; de personalidad (autoritarismo) y actitudinales (Dominación social, etnocentrismo, nacionalismo hegemónico y belicista, xenofobia). (b) el fortalecimiento del desarrollo moral y de la resistencia ante los efectos de la propaganda belicista (en combinación con el análisis de contenidos de comunicación política nacional e internacional).

Se requiere además fortalecer la personalidad, actitudes y competencias democráticas y desarrollar el conocimiento mutuo, la amistad, la empatía, la cortesía, la confianza, la solidaridad, la comunicación y la cooperación internacionales, mediante: (a) La difusión de textos que 
resalten casos históricos de cooperación bi y multinacional entre el Perú y sus países limítrofes. (b) El desarrollo de competencias para el trabajo en equipo para la solución de problemas y los encuentros grupales.

Puede además contribuir a reducir los factores psicosociales que incrementan la probabilidad de guerra el desarrollo de habilidades en resolución de conflictos que incluyan del desempeño de roles, la mediación, la negociación, el arbitraje, etc. La formación debe culminar en la estructuración de proyectos de investigación y educación para la paz para las diversas regiones del Perú con énfasis en las regiones de frontera.

Dado que un programa de esta naturaleza constituye un desafío para la creatividad educativa de centros de formación docente de los países involucrados, revisten la mayor importancia las reuniones periódicas multinacionales de formadores de docentes y de estudiantes provenientes de Facultades de Educación, Ciencias Sociales, Psicología y Comunicación Social e Institutos Pedagógicos de los seis países con el fin de intercambiar proyectos, resultados y experiencias al respecto y revisar y perfeccionar continuamente las estrategias en proceso y finalizadas.

\section{Referencias}

Aedo, S. \& Farías, M. (2009). Etnofaulismos, coprolalia, representaciones y estrategias discriminatorias: el caso del discurso chileno antiperuano. Discurso \& Sociedad, 3(3), 372-396.

Alexander, M. G., Levin, S. \& Henry, P. J. (2005). Image Theory, Social Identity and Social Dominance: Structural Characteristics and Individual Motives Underlying International Images. Political Psychology, 26(1), 27-45. https://doi. org/10.1111/j.1467-9221.2005.00408.x

Al Ganideh, S. F. \& Elahee, M. N. (2014) .Understanding AntiAmericanism among Arab Consumers: the case of Jordan. JCS, 22(1y 2), 71-87. 
Altemeyer, B. (1996). The Authoritarian Specter. Cambridge, MA: Harvard University Press.

Altemeyer, B. (1998). The Other "Authoritarian" Personality. Advances in Experimental Social Psychology, 30, 47-91. https://doi. org/10.1016/S0065-2601(08)60382-2

Altemeyer, B. (2003). What happens when Authoritarians inherith the Earth? A simulation. Analyses of Social Issues and Public Policy, 3(1), 161-169. https://doi.org/10.1111/j.1530-2415.2003.00020.x

Altemeyer, B. (2004). Highly Dominating, Highly Authoritarian Personalities. The Journal of Social Psychology, 144(4), 421-447 https://doi.org/10.3200/SOCP.144.4.421-448

Barrutieta, L. H. \& M. P. Ursúa (2011). La psicopatía subclínica y la tríada obscura de la personalidad. Psicología Conductual, 19(2), 2011, 317-331

Bendjouis, L. L. (1973). Autoritarismo y dogmatismo en entrenadores para la Reforma de la Educación-1970 (Tesis de bachiller). Pontificia Universidad Católica del Perú.

Bonilla, A. (1999). Fuerza, conflicto y negociación-Proceso político de la relación entre Ecuador y Perú. En A. Bonilla (Ed.). EcuadorPerú: Horizontes de la negociación y el conflicto. Lima, Perú: Flacso Ecuador y DESCO,

Boulding, K. (1959). National Images and International Systems. Journal of Conflict Resolution, 3, 120-131. https://doi. org/10.1177/002200275900300204

Cáceres, B. (1971). Confiabilidad, análisis de items y puntajes promedio de la Escala de Dogmatismo (Rokeach 40, Forma E) en una muestra representativa de estudiantes de la Universidad Católica del Perú. Lima: Pontificia Universidad Católica del Perú.

Cárdenas, M., Meza, P., Lagues, K., \& Yañez, S. (2010). Adaptación y validación de la Escala de Orientación a la Dominancia Social (SDO) en una muestra chilena. Universitas Psychologica, 9(1), 161-168. https://doi.org/10.11144/Javeriana.upsy9-1.aveo 
Carvacho, H. (2010) Ideological configurations and Prediction of Attitudes towards Inmigrants in Chile and Germany. International Journal of Conflict and Violence, 4(2), 221-233.

Christie, R. \& Geis, F. L. (1970). Studies in Machiavellianism. New York: Academic Press. https://doi.org/10.1016/ B978-0-12-174450-2.50006-3

Crowson, H. M. (2009a). Nationalism, internationalism, and perceived UN irrelevance: Mediators of relationships between authoritarianism and support for military aggression as part of the War on Terror. JournalofApplied Social Psychology, 39, 1137-1162. https://doi.org/10.1111/j.1559-1816.2009.00475.x

Crowson, H. M., DeBacker, T. K., \& Thoma, S. J. (2006). The role of authoritarianism, perceived threat, and need for closure or structure in predicting post-9/11 attitudes and beliefs. Journal of Social Psychology, 146, 733-750 https://doi.org/10.3200/ SOCP.146.6.733-750

Doty, R. M. et al. (1997). Authoritarianism and American Students' Attitudes about the Gulf War, 1990-1996. Personality and Social Psychology Bulletin, 23(1) (U1997uy): 1133-1143 https://doi. org/10.1177/01461672972311002

Duckitt, J., Wagner, C., du Plessis, I. \& Birum. I. (2002). The Psychological Bases of Ideology and Prejudice: Testing a Dual Process Model. Journal of Personality and Social Psychology, 83(1), 75-93. https://doi.org/10.1037/0022-3514.83.1.75

Echeverri Cañas, L. M., Horst, E., \& Parra, H. J. (2015). Imagen país de Colombia desde la perspectiva extranjera. Arbor, 191(773), a244. https://doi.org/10.3989/arbor.2015.773n3014

Espinosa, A. \& Córdova, C. (2013). Autoritarismo, actitudes políticas y participación politica. Cuadernos de Investigación, $\mathrm{N}^{\circ} 3$. Lima: IOP PUCP.

Espinosa, A., Schmitz, M., \& de Rojas, J. M. R. (2016). Ideological basis of National Identity and their Influence on subjective, psychological and social well-being in Peru. Limite-Revista Interdisciplinaria de Filosofía y Psicología, 11(35). 
Genna, K., Espinosa, A., \& Páez, D. (2010). Cómo los vemos, cómo nos vemos: influencia de la comparación social entre Perú y Chile en la identidad nacional peruana. Psicología Politica, (41), 81-108

González, A. (2014). Perú-Chile: imágenes mutuas. Liberabit, 20(1). Enero 2014,13-28

González, R., Sirlopú, D., \& Kessler, T. (2010). Prejudice among Peruvians and Chileans as a function of identity, intergroup contact, acculturation preferences, and intergroup emotions. Journal of Social Issues, 66(4), 803-824 https://doi. org/10.1111/j.1540-4560.2010.01676.x

Guido, G., Prete, M. I., Tedeschi, P., \& Dadusc, L. (2010). Effects of Jewish-Italian animosity towards Arab products: The role of personality. Marketing Management Journal, 20(1), 1-18, 18-32

Hurtado, A. M. \& Aponte, J. (2017). ¿Hacia un gobierno transfronterizo? Explorando la institucionalidad para la "integración" colombo-peruana. Estudios Fronterizos, 18(35), 70-89 https:// doi.org/10.21670/ref.2017.35.a04

Ibáńez, C. (2013). Percepción de la relación Chile-Perú y su influencia en la identidad nacional, las representaciones estereotípicas y los prejuicios hacia el exogrupo nacional (Tesis de licenciatura). Pontificia Universidad Católica del Perú, Lima.

Janos, E., Espinosa, A., \& Pacheco, M. (2018). Bases Ideológicas de la Percepción del Sistema Normativo y el Cinismo Político en Adultos de Sectores Urbanos del Perú. Psykhe 27(1) https://doi. org/10.7764/psykhe.27.1.1176

Jones, R. E. \& Melcher, B. H. (1982). Personality and the preference for modes of conflict Resolution. Human Relations, 35(8),649-658 https://doi.org/10.1177/001872678203500803

Kahhat, F. (2006). Las relaciones Chile-Perú en el ámbito de la seguridad: Entre la cooperación y la desconfianza. Revista Fuerzas Armadas y Sociedad, 20(1), 3-16.

Kerlinger, F. N. (1966). Foundations of Behavioral Research. New York: Holt, Rinehart and Winston, Inc. 
Kosterman, R. \& Feshback, S.(1989) Toward a Measure of Patriotic and Nationalistic Attitudes. Political Psychology, 10(2), 257-274 https://doi.org/10.2307/3791647

Langman, L. (2006). The Social Psychology of Nationalism: To Die for the Sake of Strangers. En G. Delanty y K. Kumar (Eds.). The Sage Handbook of Nations and Nationalism. London: Sage.

Leite, E. L., Ferreira, A. S. S., Batista, J. R. M., Estramiana, J. L. Á., \& Torres, A. R. R. (2018). Nacionalismo, Patriotismo e Essencialismo na Construcao da identidade nacional brasileira. Trends,Psycholo, 26(4). Riberao Preto, Oct./Dec. https://doi. org/10.9788/TP2018.4-13Pt

Maldonado, G. \& Crow, D. (2011) ¿Cómo se ubica América Latina en el mundo? Opiniones y actitudes de los latinoamericanos hacia países y regiones. Revista Mexicana de Politica Exterior, 93, juliooctubre, 195-234.

Malpica, C. N. \& González, A. (1999). Imágenes internacionales PerúEcuador. En A. Bonilla (Ed.). Ecuador-Perú: Horizontes de la negociación y el conflicto. Lima: Flacso Ecuador y DESCO.

McFarland, S. G. (2005). On the Eve of War: Authoritarianism, Social Dominance and American Student's atttitudes toward attacking Iraq, Personality and Social Psychology Bulletin, 31(3), 360-367 https://doi.org/10.1177/0146167204271596

Miglietta, A., Tartaglia, S., \& Loera, B. (2018). Los valores personales y la aceptación de inmigrantes: ¿Por qué es importante la identificación nacional? Revista de Psicología Social. Mayo 2018, https:// doi.org/10.1080/02134748.2018.1482058

Mueller, J. I. (1969). Approaches to measurement in international relationsA non evangelical survey. New York: Appleton Century-Crofts.

Naciones Unidas (1998). Cultura de la Paz, Resolución A/RES/52/13, 15 de enero 1998.

Novak, F. \& Namihas, S. (2010). Perú-Ecuador: Una experiencia de paz y buena vecindad. Lima: Instituto de Estudios Internacionales (IDEI) de la Pontificia Universidad Católica del Perú. Fundación Konrad Adenauer. 
Novak, F. \& Namihas, S. (2011). Perú-Colombia: La construcción de una asociación estratégica y un desarrollo fronterizo. Lima: Instituto de Estudios Internacionales (IDEI) de la Pontificia Universidad Católica del Perú. Fundación Konrad Adenauer.

Novak, F. \& Namihas, S. (2012). Las relaciones entre Perú y Brasil. Lima: Instituto de Estudios Internacionales (IDEI) de la Pontificia Universidad Católica del Perú. Fundación Konrad Adenauer.

Novak, F. \& Namihas, S. (2013). Las relaciones entre Perú y Bolivia. Lima: Instituto de Estudios Internacionales (IDEI) de la Pontificia Universidad Católica del Perú. Fundación Konrad Adenauer.

Osgood, C. E., Suci, G. J., \& Tannenbaum, P. H. (1957). The Measurement of Meaning. Urbana, IL: University of Illinois Press.

Palmer, D. S. (1999). El papel de los garantes. En A. Bonilla (Ed.), Ecuador-Perú: Horizontes de la negociación y el conflicto. Lima, Perú: Flacso Ecuador y DESCO.

Parodi, D. (2010). Lo que dicen de nosotros. La Guerra del Pacifico en la historiografia y textos escolares chilenos. Lima: Universidad Peruana de Ciencias Aplicadas. https://doi. org/10.19083/978-612-4041-56-3

Pratto, F., Sidanius, J., Stallworth, L. M. \& Malle, B. F. (1994). Social Dominance Orientation: A personality variable predicting social and political attitudes. Journal of Personality and Social Psychology, 72, 37-53 https://doi.org/10.1037/0022-3514.67.4.741

Proyecto Educación y Cultura de Paz, (2002). Lima: Pontificia Universidad Católica del Perú.

Psychologists for Social Responsibility (2003). Enemy Images-A resource Manual for Reducing Enmity. Washington, D.C.: PSR.

Rokeach, M. (1960). The Open and Closed Mind. New York, Basic Books.

Rottenbacher J. M., Espinosa, A. \& Magallanes, J. M. (2011) Analizando el prejuicio: bases ideológicas del racismo, el sexismo y la 
homofobia en una muestra de habitantes de la ciudad de Lima. Psicología Politica, 11(22), 225-246.

Rottenbacher, J. M. (2012) Conservadurismo político y rigidez cognitiva en una muestra de estudiantes y egresados universitarios de la ciudad de Lima. Avances en Psicología Latinoamericana. Bogotá (Colombia),30(2),257-271.

Rottenbacher, J. M. \& Schmitz, M. (2012) Conservadurismo político y tolerancia hacia los comportamientos transgresores. Psicología Politica, 44, 31-56

Sidanius, J. \& Pratto, F. (1999). Social Dominance: An Intergroup Theory of Social Hierarchy and Oppression. Cambridge University Press: Cambridge. https://doi.org/10.1017/CBO9781139175043

Sirlopú, D. \& León, R. (2016). Actitudes hacia la paz y la guerra, identidad social e ideología en universitarios peruanos. En I. Magaña, A. Dorna \& I. Torres (Eds.), Contribuciones a la psicología politica en América Latina: Contextos y escenarios actuales (pp. 99-219). Santiago: RIL Editores.

Torabian, S. \& Abalakina, M. (2012) Attitudes toward war in United States and Iran. Iranian Studies, 45(4), 463-478. https://doi.org /10.1080/00210862.2012.673825

Valencia-Moya, J., Espinosa, A., Jiménez, V., \& Romero, J. C. (2018) Ideología, identidad nacional, representaciones estereotípicas y valoración exogrupa: UN estudio sobre las relaciones entre Perú y Chile. Interciencia, Caracas, 43(5), 304-312.

Zambrano-Mora, A., León, R., \& Escurra, L. (2017). Imagen del Perú y los peruanos en un grupo de universitarios chilenos. Persona, (20), 95-112 https://doi.org/10.26439/persona2017.n20.1742

Recibido: 7/6/2019

Revisado: 5/11/2020

Aceptado: 22/11/2020 